\title{
Reevaluation of the Beam and Radial Hypotheses of Parallel Fiber Action in the Cerebellar Cortex
}

\author{
Samuel W. Cramer, ${ }^{\star}$ Wangcai Gao, ${ }^{\star}$ Gang Chen, and Timothy J. Ebner \\ Department of Neuroscience, University of Minnesota, Minneapolis, Minnesota 55455
}

The role of parallel fibers (PFs) in cerebellar physiology remains controversial. Early studies inspired the "beam" hypothesis whereby granule cell (GC) activation results in PF-driven, postsynaptic excitation of beams of Purkinje cells (PCs). However, the "radial" hypothesis postulates that the ascending limb of the GC axon provides the dominant input to PCs and generates patch-like responses. Using optical imaging and single-cell recordings in the mouse cerebellar cortex in vivo, this study reexamines the beam versus radial controversy. Electrical stimulation of mossy fibers (MFs) as well as microinjection of NMDA in the granular layer generates beam-like responses with a centrally located patch-like response. Remarkably, ipsilateral forepaw stimulation evokes a beam-like response in Crus I. Discrete molecular layer lesions demonstrate that PFs contribute to the peripherally generated responses in Crus I. In contrast, vibrissal stimulation induces patch-like activation of Crus II and $\mathrm{GABA}_{\mathrm{A}}$ antagonists fail to convert this patch-like activity into a beam-like response, implying that molecular layer inhibition does not prevent beam-like responses. However, blocking excitatory amino acid transporters (EAATs) generates beam-like responses in Crus II. These beam-like responses are suppressed by focal inhibition of MF-GC synaptic transmission. Using EAAT4 reporter transgenic mice, we show that peripherally evoked patch-like responses in Crus II are aligned between parasagittal bands of EAAT4. This is the first study to demonstrate beam-like responses in the cerebellar cortex to peripheral, $\mathrm{MF}$, and GC stimulation in vivo. Furthermore, the spatial pattern of the responses depends on extracellular glutamate and its local regulation by EAATs.

\section{Introduction}

Parallel fibers (PFs) make 100,000-200,000, excitatory glutamatergic synapses on the dendritic trees of Purkinje cells (PCs) (Eccles et al., 1967). Despite their massive numbers and striking mediolateral geometry, there are two markedly different views of the role of PFs in cerebellar cortical function. The classic "beam" hypothesis postulates that mossy fiber (MF) activation of granule cells (GCs) results in beam-like excitation of PCs (Braitenberg and Atwood, 1958; Braitenberg, 1961). In support of this hypothesis, MF input evokes field potentials in the molecular layer well outside of the MF termination area (Garwicz and Andersson, 1992), whisker stimulation comodulates transversely located PCs (Bosman et al., 2010), and the presence of synchrony in the simple spike firing during natural inputs (De Zeeuw et al., 1997). However, the beam hypothesis is controversial as others reported that peripheral or MF inputs evoke only patches of PC or molec-

\footnotetext{
Received Feb. 15, 2013; revised May 23, 2013; accepted May 27, 2013.

Author contributions: T.J.E. designed research;S.W.C., W.G., and G.C. performed research;S.W.C., W.G., G.C., and T.J.E. analyzed data; S.W.C., W.G., G.C., and T.J.E. wrote the paper.

This work was supported in part by National Institutes of Health Grants R01 NS18338, P01 NS058901, P30 NS062158, F31 NS080338, T32 GM008244, and T32 GM008471. We thank Michael McPhee for generating the graphics, Kris Bettin for preparation of the manuscript, and Dr. Jeffrey Rothstein at the Johns Hopkins University for generously providing the EAAT4 reporter mice.

The authors declare no competing financial interests.

*S.W.C. and W.G. contributed equally to this work.

Correspondence should be addressed to Dr. Timothy J. Ebner, Department of Neuroscience, University of Minnesota, Lions Research Building, Room 421, 2001 Sixth Street SE, Minneapolis, MN 55455. E-mail: ebner001@umn.edu.

DOI:10.1523/JNEUROSCI.0711-13.2013

Copyright $\odot 2013$ the authors $\quad 0270-6474 / 13 / 3311412-13 \$ 15.00 / 0$
}

ular layer activity (Bower and Woolston, 1983; Cohen and Yarom, 1998; Rokni et al., 2007; Santamaria et al., 2007). Others found little temporal synchrony in the simple spike discharge of PCs separated transversely by $>100 \mu \mathrm{m}$ (Bell and Grimm, 1969; Ebner and Bloedel, 1981; Shin and De Schutter, 2006; Heck et al., 2007).

The alternative hypothesis is based on the radial organization of GC axons as they ascend to the molecular layer and make synaptic contacts on PCs (Llinas, 1982; Napper and Harvey, 1988; Gundappa-Sulur et al., 1999; Santamaria et al., 2002; Santamaria and Bower, 2005; Lu et al., 2009). This "radial" hypothesis postulates that GC ascending axons provide the dominant input to PCs and that PCs located laterally are very weakly activated by PFs. Compared with PF synapses, the synaptic connections made along the ascending limb are argued to be stronger, have a higher number of connections on a PC, and result in more synchronous activation of PCs (Llinas, 1982; Isope and Barbour, 2002; Sims and Hartell, 2005). Modeling studies found little role for PFs in modulating PC simple spike discharge, suggesting instead PFs provide background tone (Santamaria and Bower, 2005; Santamaria et al., 2007).

There are major concerns with the radial hypothesis. The ascending limb provides only 3-6\% of the total synapses on a PC (Napper and Harvey, 1988; Huang et al., 2006; Lu et al., 2009). In the cerebellar slice, synaptic strength between ascending GC axons and PCs, and between PFs and PCs is equivalent, and PFs activate PCs for several hundred microns (Isope and Barbour, 2002; Walter and Khodakhah, 2009). A variant of the radial hypothesis proposes that GABAergic, molecular layer inhibition 
A Background

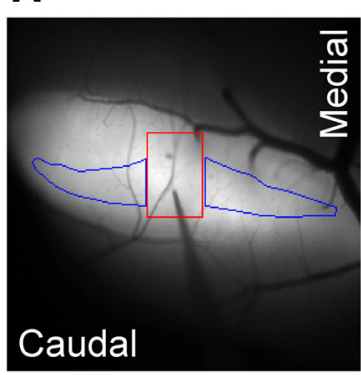

WM Stimulation

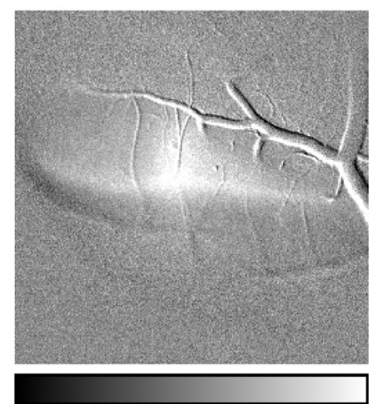

\section{APV/LY367385}
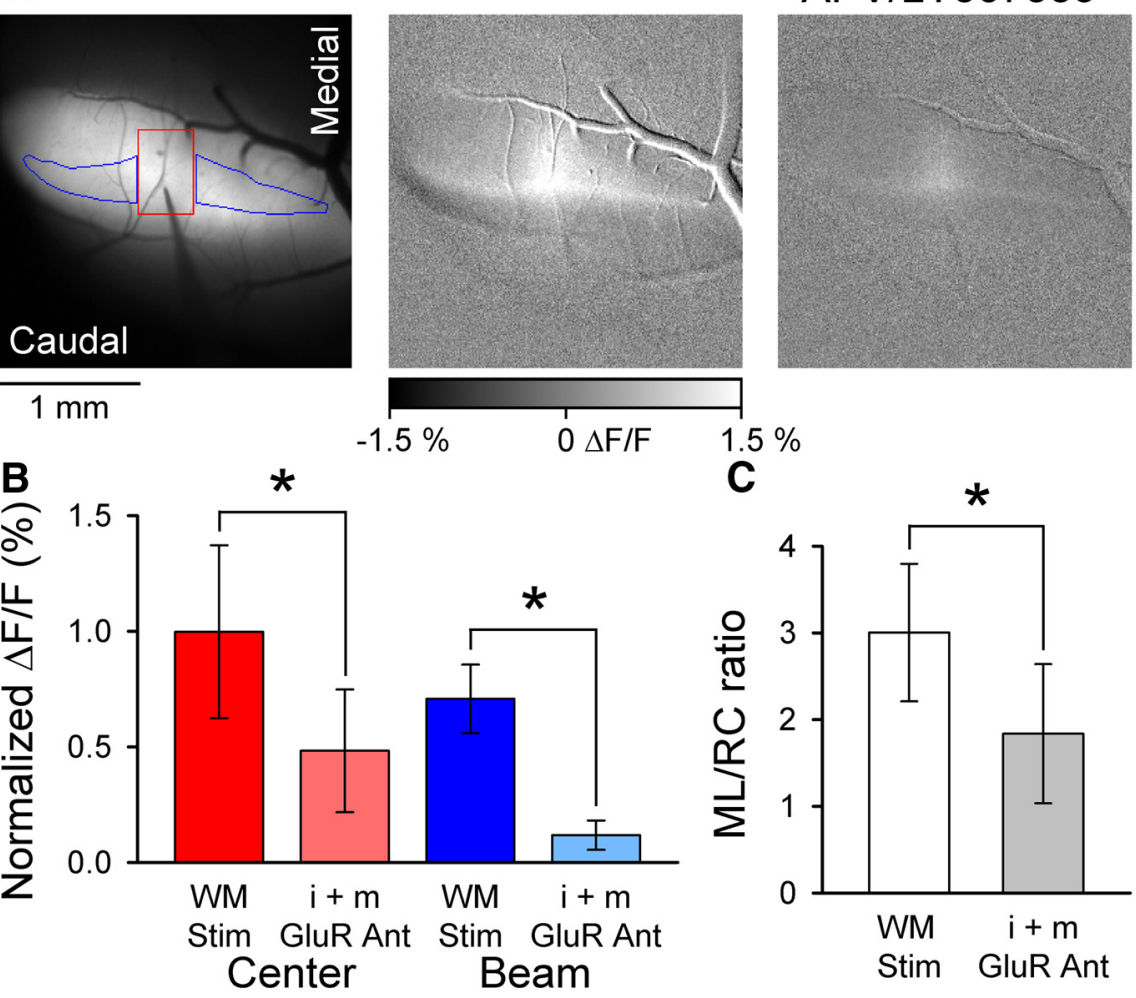

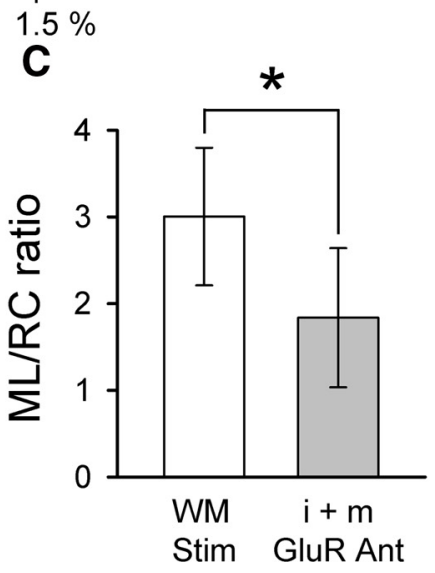

Figure 1. WM stimulation evokes beam-like responses. $\boldsymbol{A}$, Left, Background fluorescence image of Crus II after injection of Oregon Green. Also shown is electrode placement within the folium and ROls used to quantify the center (red) and beam (blue) components of the fluorescence response. Microelectrode was lowered to a depth of $500 \mu \mathrm{m}$ below the surface. Middle, The beam-like $\mathrm{Ca}^{2+}$ response to WM stimulation $(200 \mu \mathrm{A}, 100 \mu$ s pulses at $100 \mathrm{~Hz}$ for $100 \mathrm{~ms})$. Right, The beam response is largely blocked by i+mGluR antagonists (100 $\mu \mathrm{m}$ DNQX, $250 \mu \mathrm{m}$ APV, and $200 \mu \mathrm{m}$ LY367385). B, Summary data (mean \pm SD, $n=4$ mice) for the center and beam response components before and after block by GluR antagonists. ${ }^{*} p<0.05$. C, Summary ML/RC data for WM stimulation (open bar) and after (filled gray bar) application of $i+$ mGluR antagonists ( $n=4$ mice).

prevents beam-like activation by PFs (Santamaria et al., 2002, 2007).

The present study reevaluated the beam versus radial hypothesis, using optical imaging to map spatial patterns of activation in vivo. The results show beam-like activation in response to MF, GC, and peripheral stimulation. Furthermore, GABAergic inhibition does not prevent beam-like responses. Instead, the nonuniform distribution of excitatory amino acid transporter isoform 4 (EAAT4) on PCs (Nagao et al., 1997; Dehnes et al., 1998) and regulation of extracellular glutamate concentration may contribute to the pattern of PC activation.

\section{Materials and Methods}

Animal preparation. Both FVB (Charles River Laboratories) and EAAT4 reporter mice on a $C 57 B L / 6$ background were used for experiments in this study (Gincel et al., 2007). For both lines, mice of either sex were used. All animal experimentation was approved by and conducted in conformity with the Institutional Animal Care and Use Committee of the University of Minnesota. Detailed descriptions of the preparation of animals for optical imaging have been described in previous publications (Reinert et al., 2004; Gao et al., 2006) and are only described briefly. Adult mice 3-8 months of age were anesthetized by an initial intramuscular injection of $2 \mathrm{mg} / \mathrm{kg}$ acepromazine followed by an intraperitoneal injection of $2 \mathrm{mg} / \mathrm{kg}$ urethane and supplemented with $1.5 \mathrm{mg} / \mathrm{kg}$ urethane as needed. Animals were placed in a stereotaxic frame, mechanically ventilated, and their body temperature feedback regulated. Depth of anesthesia was monitored via electrocardiogram and testing for responses to somatosensory stimuli. A craniotomy ex- posed Crus I and Crus II, and then a watertight acrylic chamber was constructed around the exposed folia and filled with Ringer's solution gassed with $95 \% \mathrm{O}_{2}$ and $5 \% \mathrm{CO}_{2}$.

Drug administration. Bicuculline [1(s), 9(R)(-)-bicuculline methochloride], GABAzine (SR-95531), glycine (L-glycine), and NMDA ( $N$ methyl-D-aspartate) were purchased from Sigma. TBOA (DL-threo- $\beta$-benzyloxyaspartic acid), DNQX (6,7-dinitroquinoxaline-2,3dione), LY $367385 \quad[(S)-(+)-\alpha$-amino-4carboxy-2-methylbenzeneacetic acid], and APV (D-(-)-2-amino-5-phosphonopentanoic acid) were purchased from Tocris Bioscience. All drugs were dissolved in normal Ringer's solution and applied to the cerebellar surface by replacing the solution in the optical chamber, except for DNQX/APV and NMDA/glycine, which were microinjected into the cerebellar cortex.

Simulation, microinjection, lesioning, and electrophysiological techniques. A paralyenecoated tungsten microelectrode $(2-5 \mathrm{M} \Omega$, Fredrick Haer) was used to activate MF afferents in the cerebellar white matter (WM). Typical parameters for MF stimulation consisted of six pulses of $100-150 \mu \mathrm{A}, 100-200 \mu$ s at 100 Hz. PF stimulation consisted of 10 pulses of $100-125 \mu \mathrm{A}, 100 \mu \mathrm{s}$ at $100 \mathrm{~Hz}$. Peripheral responses were evoked via bipolar stimulation with two electrodes placed $\sim 1 \mathrm{~mm}$ apart either surrounding the ipsilateral C3 vibrissa follicle or in the medial and lateral walking pads on the ventral aspect of the forepaw using $20 \mathrm{~V}, 300 \mu \mathrm{s}$ pulses at $10 \mathrm{~Hz}$ for $10 \mathrm{~s}$ (Gao et al., 2006) or $10-20 \mathrm{~V}, 300 \mu$ s pulses at $100 \mathrm{~Hz}$ for $50-100$ $\mathrm{ms}$, respectively.

Microinjections of NMDA/glycine or DNQX/APV into the cerebellar cortex were performed by lowering a glass micropipette (1-5 $\mathrm{M} \Omega$ ) beneath the cerebellar surface and triggering single ejection pulses $(75-100 \mathrm{kPa}$, $100-400 \mathrm{~ms}$ ) using a pico-injection system (PLI-100; Medical Systems). The injection parameters were set to deliver as small a volume as possible over a brief duration. The volume of the injection was calculated by collecting an image of the droplet produced upon injection. The image allowed the diameter of the droplet to be measured and the volume (assumed to be spherical) calculated.

In some experiments, lesions were generated in the molecular layer. After evoking a beam with PF stimulation, a tungsten microelectrode was used to produce electrolytic lesions across the beam. Typically, lesions were made at $3-5$ locations $(50 \mu \mathrm{A}, 1 \mathrm{~s})$ to just span the width of the beam. After generating the lesions, the response to PF stimulation was evoked to assess the effectiveness and extent of the lesion, followed by histological verification (see below).

Single-unit extracellular recordings of cerebellar neurons used glasscoated, platinum iridium microelectrodes (1-2 M $\Omega$; Alpha Omega) and conventional electrophysiological techniques (Chen et al., 2009). Recordings were restricted to the molecular layer where PCs were identified by the presence of spontaneous simple spikes and complex spikes (Gao et al., 2006). All other neurons were classified as unidentified cerebellar neurons. Recordings were digitized at $32 \mathrm{kHz}$ and stored online for off-line analysis.

Optical imaging. The anesthetized animal in the stereotaxic frame was placed on an $x-y$ stage mounted on a modified Nikon epifluorescence microscope fitted with a $4 \times$ objective. Images of Crus I were acquired with a Quantix cooled charge coupled device camera with 12 bit digitization (Roper Scientific). A $100 \mathrm{~W}$ mercury-xenon lamp (Hamamatsu Photonics) with direct current controlled power supply (Opti Quip) was used as the light source. Images were binned $2 \times 2$ to yield images of $256 \times 256$ pixels with a resolution of $\sim 10 \times 10 \mu \mathrm{m}$ per pixel. 
$\mathrm{Ca}^{2+}$ imaging was performed by first loading the $\mathrm{Ca}^{2+}$ dye via a series of microinjections into the imaging field. The solution consisted of $10 \mathrm{~mm}$ Oregon Green 488 BAPTA-1/AM (Invitrogen) dissolved in DMSO plus 20\% Pluronic F-127 solution (Invitrogen) and diluted 20 times in normal Ringer's solution (Stosiek et al., 2003; Sullivan et al., 2005; Gao et al., 2006). A glass micropipette (resistance 1-5 M $\Omega$ ) was filled with the dye solution and lowered to a depth of $\sim 150-300 \mu \mathrm{m}$ in the cerebellar cortex. Injections were made in $\sim 15$ locations to uniformly stain the folium of interest, and the preparation was then incubated for $30 \mathrm{~min}$ to allow the $\mathrm{Ca}^{2+}$ dye to equilibrate. Images were captured using a custom $\mathrm{Ca}^{2+}$ filter set with excitation at 490-510 $\mathrm{nm}$, a long-pass dichroic mirror of $515 \mathrm{~nm}$, and emission at 520-530 $\mathrm{nm}$. Flavoprotein autofluorescence imaging used a bandpass excitation filter (455 \pm 35 $\mathrm{nm})$, a dichroic mirror (500 $\mathrm{nm})$, and a $>515$ $\mathrm{nm}$-long pass emission filter (Reinert et al., 2004; Gao et al., 2006).

Optical imaging data analysis. A series of $\mathrm{Ca}^{2+}$ or flavoprotein images consisting of $40-$ 310, $200 \mathrm{~ms}$ frames (5 frames/s) was acquired. Difference images were then generated by subtracting the average of nine control frames (control average) from each control and experimental frame. These difference images were then divided by the control average, yielding images in which the intensity of each pixel reflects the $\Delta \mathrm{F} / \mathrm{F}$ change in fluorescence relative to the control average.

As shown in Figures 1 and 2, MF stimulation and microinjection of NMDA/glycine resulted in beam-like responses with a centrally located increase in $\mathrm{Ca}^{2+}$ fluorescence. Quantification aimed to capture both aspects of the responses. Therefore, regions of interest (ROIs) were placed on the beam-like responses medial and lateral to the stimulation/microinjection (beam component). A rectangular region (area of $2500 \mu \mathrm{m}^{2}$ ) centered over the stimulation/microinjection site (center component) was also measured. This approach was also applied to the beam-like response evoked in Crus II by vibrissal stimulation in the presence of TBOA and to the beam responses evoked by direct PF stimulation (see Fig. 10) The center ROI was placed on the patch-like region evoked in the absence of TBOA, and the beam regions placed on the areas of increased fluorescence that extended medially and laterally from the patch in the presence of TBOA. The average $\Delta \mathrm{F} / \mathrm{F}$ response corresponding to peak activation (three frames) was determined for each ROI and averaged for each series.

For peripheral, WM, and GC stimuli, we used the following method to quantify the length of the evoked responses parallel to the long axis of the folium, referred to as mediolateral axis (ML), and along the perpendicular axis, referred to as rostrocaudal axis (RC). The dimensions of the evoked responses were measured by first generating images of the significant evoked responses by first low-pass filtering $(3 \times 3)$ the $\Delta \mathrm{F} / \mathrm{F}$ image and then determining the mean and SD of a control region. The pixels above or below this mean \pm 2 SD were pseudocolored, aligned, and superimposed on an image of the folia using a custom program written in MATLAB (MathWorks). Based on this thresholding, a $100 \times 100 \mu \mathrm{m}$ grid was overlaid on the response region, and the response dimensions were then measured along the $\mathrm{RC}$ and the ML axes of the folium. The ML and RC lengths were determined for each $100 \mu \mathrm{m}$ section of the grid, and the ratio of the average ML and RC lengths (ML/RC) was computed.
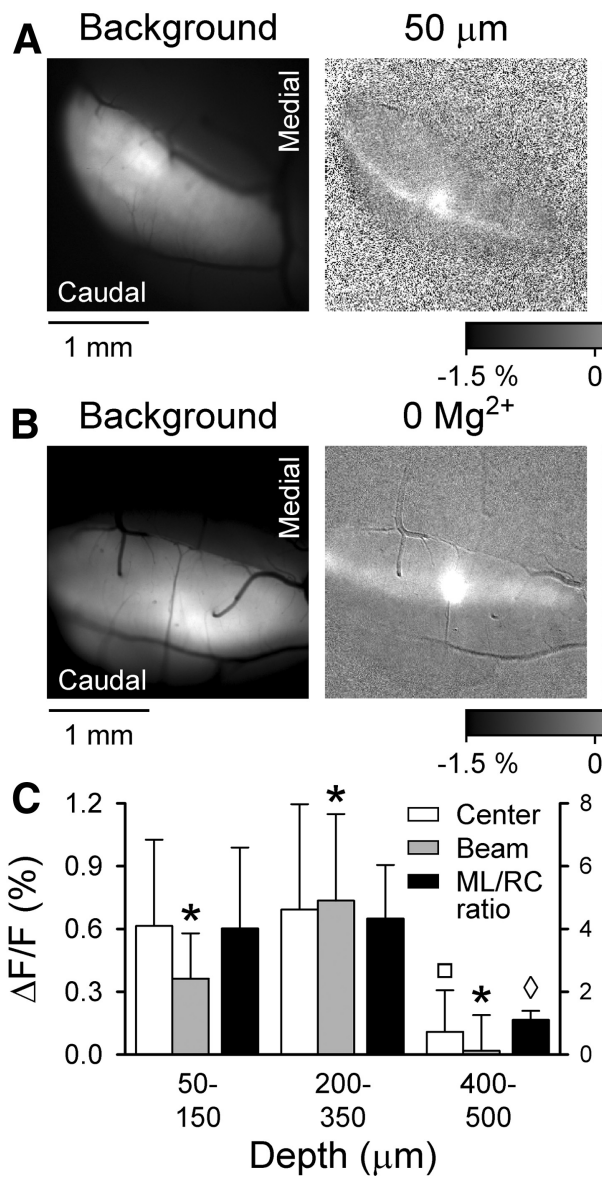

Figure 2. Granular layer stimulation by NMDA evokes beam-like response. $A$, Cerebellar activation evoked by NMDA/glycine microinjection. Left, Background fluorescence of Crus II followed by a series of grayscale images to the right showing typical $\mathrm{Ca}^{2+}$ responses to $\mathrm{NMDA} /$ glycine microinjections at 50,200 , and $400 \mu$ m below the cerebellar surface. Peak beam-like activity is evoked when NMDA/glycine NMDA receptor-mediated, NMDA injections were performed at a depth evoking a maximal response in the $0 \mathrm{~mm} \mathrm{Mg}^{2+}$ Ringer's solution

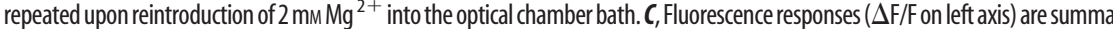
three depth ranges below the cerebellar surface ( $n=9$ mice). The * $\square>$ values are significantly different from all other values in the same group (i.e., control, beam, ML/RC). The $\diamond$ indicates the $\mathrm{ML} / \mathrm{RC}$ ratio for injection at $400-500 \mu \mathrm{m}$ is significantly different from the $\mathrm{ML} / \mathrm{RC}$ ratio for injections at either $50-150$ or $200-130 \mu \mathrm{m}$. D. Summary fluorescence responses and $\mathrm{ML} / \mathrm{RC}$ ratios for NMDA/glycine injections with and without $\mathrm{Mg}^{2+}$. The ${ }^{*}, \square, \diamond$ values are significantly different from all other values in the same group (i.e., control, beam, ML/RC). The $\diamond$ indicates the $\mathrm{ML} / \mathrm{RC}$ ratio for injection at $400-500$ $\mu \mathrm{m}$ is significantly different from the $\mathrm{ML} / \mathrm{RC}$ ratio for injections at either $50-150$ or $200-130 \mu \mathrm{m}$.

The quantification of the beam-like response in Crus I followed a similar procedure as that described for the NMDA/glycine microinjection and MF stimulation experiments. However, multiple ROIs were defined corresponding to the medial and lateral portion of the beam-like response. The region of the folium where the molecular layer was lesioned was omitted from analyses (Fig. 5, example ROIs). This procedure was repeated after lesioning to compare the peripherally evoked $\Delta \mathrm{F} / \mathrm{F}$ response on-beam before and after the PF disruption.

Example grayscale images displayed in Figures 1, 2, and 3 were constructed by averaging 4-32 trials pixel by pixel and then averaging the 5-10 frames encompassing the maximum of the response of interest. Resultant images were scaled to $\pm 1.5 \% \Delta \mathrm{F} / \mathrm{F}$ for grayscale display using MetaMorph (Molecular Devices).

To quantify the spatial relationship between the peripherally evoked optical responses and the distribution of EAAT4, an ROI for the region with the response was identified by thresholding the $\Delta \mathrm{F} / \mathrm{F}$ response to define the portion of the folia exhibiting the peak evoked fluorescence. The $\Delta \mathrm{F} / \mathrm{F}$ along the ROI was determined for both the $\mathrm{Ca}^{2+}$ indicator responses and the background fluorescence, which are related to the 
A
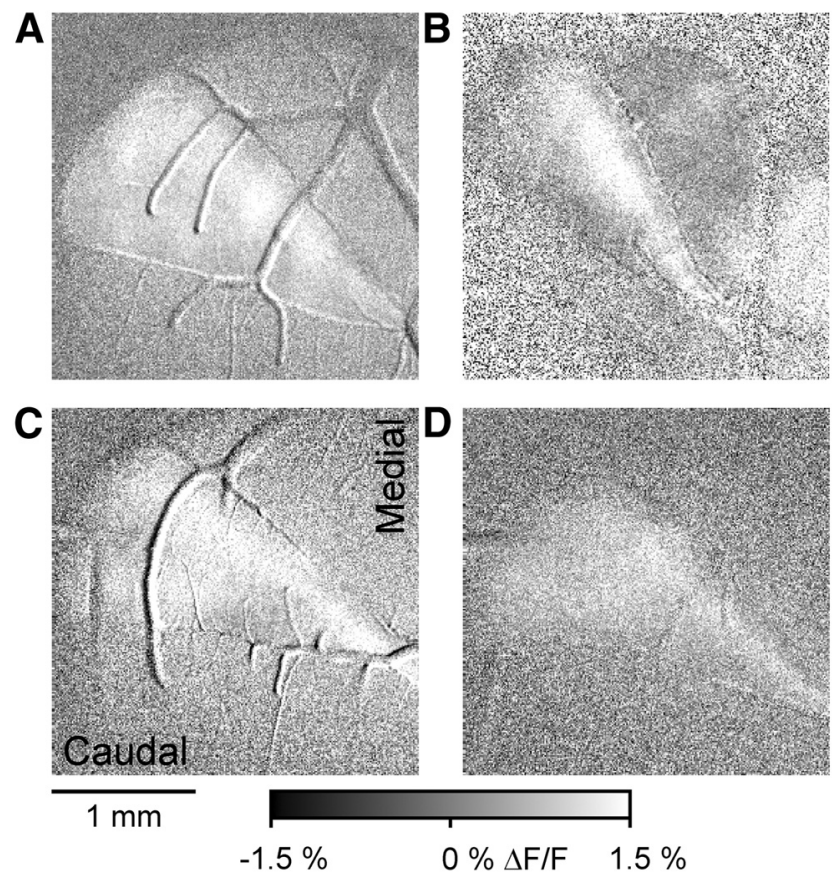

Figure 3. Ipsilateral forelimb stimulation evokes beam-like responses in Crus I. $A-D$, Four examples of the beam-like $\mathrm{Ca}^{2+}$ responses evoked by bipolar electrical stimulation applied to the ipsilateral forepaw $(10-20 \mathrm{~V}, 300 \mu$ s pulses at $100 \mathrm{~Hz}$ for $50-100 \mathrm{~ms})$. Each example is from a different mouse. The $\mathrm{Ca}^{2+}$ images are shown as $\Delta \mathrm{F} / \mathrm{F}$ obtained by subtraction of averaged baseline images from images obtained during the stimulus (see Materials and Methods) and displayed with grayscale.

EAAT4 expression level, across the folium. The correlation coefficient $(\rho)$ between these two $\Delta \mathrm{F} / \mathrm{F}$ spatial profiles was computed.

Electrophysiology analysis. Analysis of single-unit recordings consisted of constructing peristimulus time histograms ( $1 \mathrm{~ms}$ bins) of spike firing $10 \mathrm{~ms}$ before stimulus onset and $40 \mathrm{~ms}$ poststimulus using Spike 2 (Cambridge Electronic Design). The number of trials ranged from 100 to 200. Cells were counted as responding to the stimulus if $\geq 3$ consecutive poststimulus bins contained firing rates greater or less than the prestimulus baseline mean \pm 2 SDs. The latency of the response was defined as the bin with the first significant increase or decrease (onset), and the end of the response (offset) was the bin at which the firing no longer differed significantly from baseline. The duration of the response was defined as the time between onset and the offset. Response amplitude was defined as the average change in firing during the response compared with mean baseline firing. Percentage change in firing from baseline was used to normalize for different firing rates among neurons.

Histology. After the experiment, animals were transcardially perfused with $1 \%$ PBS followed by $4 \%$ paraformaldehyde in phosphate buffer $(\mathrm{pH}$ 7.4). Brains were then extracted, postfixed in paraformaldehyde for $2 \mathrm{~h}$, and cryoprotected in $30 \%$ sucrose. Cryosectioning of the cerebellum was performed to obtain $40-\mu \mathrm{m}$-thick, coronal sections that were thionine stained for lesion identification.

Statistical analysis. The statistical analysis was performed using SAS (SAS Institute). The effects of various drugs, prelesion and postlesion responses, and on versus off patch single-unit response latency were statistically evaluated using a paired Student's $t$ test. $\Delta \mathrm{F} / \mathrm{F}$ responses evoked by microinjection of NMDA/glycine at various depths below the cerebellar cortex were statistically evaluated with ANOVA (within-subject design with repeated measures) followed by Bonferroni post hoc test $(p<0.01)$. In the text and figures, all values are reported as mean $\pm \mathrm{SD}$. When describing the results of an experiment, $n$ refers to the number of animals used.

\section{Results}

\section{WM stimulation evokes a beam-like response}

The initial in vivo experiment used $\mathrm{Ca}^{2+}$ imaging to examine the spatial distribution of cerebellar cortical activation in response to MF input. To directly activate MFs, a microelectrode aligned approximately perpendicular to the surface of Crus II was lowered to a depth of $450-500 \mu \mathrm{m}$, and stimuli were delivered to the WM. In the FVB mouse, the molecular layer, PC layer, and granular layer combined are $\sim 440 \mu \mathrm{m}$ thick (Serinagaoglu et al., 2007; Oz et al., 2011). The example response reveals beam-like activation of the cerebellar cortex along the entire folium with a centrally located, patch-like response above the stimulation site (Fig. 1A). Similar responses were observed in each mouse tested $(n=7)$, consistent with activation of a group of GCs by MF afferents that in turn leads to PF activation of PCs. The results also are consistent with a strong local activation above the site of WM stimulation that likely includes excitation of PCs by ascending GC axons (Llinas, 1982; Cohen and Yarom, 1998; Isope et al., 2002; Walter et al., 2009).

To determine the presynaptic versus postsynaptic nature of the response, a mixture of ionotropic and metabotropic glutamate receptor (i+mGluR) antagonists (100 $\mu \mathrm{M}$ DNQX, $200 \mu \mathrm{M}$ LY 367385, and $250 \mu \mathrm{M}$ APV to antagonize AMPA, mGluR1, and NMDA receptors, respectively) was added to the optical chamber Ringers. The example images show a large reduction in the response in the presence of the $\mathrm{i}+\mathrm{mGluR}$ antagonists (Fig. 1A). Although both the center and beam components were reduced significantly compared with baseline (center, $t_{(3)}=87.31, p<$ 0.0001 and beam, $t_{(3)}=9.31, p=0.0026$, Fig. $1 B$ ), the beam component had the larger decrease $(83 \pm 16 \%)$. This finding demonstrates that the beam-like response is primarily postsynaptic. A small beam-like response remains that likely represents a $<100 \%$ block of synaptic transmission. In the presence of $\mathrm{i}+\mathrm{mGluR}$ antagonists, $51 \pm 45 \%$ of the center response remains. Both direct activation of CF afferents (presynaptic component) and antidromic activation of PCs likely contribute to the remaining response. Indeed, the center response has a parasagittal shape consistent with the projection pattern of the CF afferents (Sasaki et al., 1989; Chen et al., 1996). To quantify the geometry of the response evoked by WM stimulation, we measured the length of the response along the ML and $\mathrm{RC}$ axes of the folium and determined the ratio of the $\mathrm{ML} / \mathrm{RC}$ axes. The $\mathrm{ML} / \mathrm{RC}$ ratio is also used in subsequent experiments to compare the geometry of the responses evoked by different stimuli. The ML/RC ratio for WM stimulation was $3.00 \pm 0.79$ (Fig. 1C). Upon application of $\mathrm{i}+\mathrm{mGluR}$ antagonists, the ratio decreased significantly to $1.84 \pm$ $0.80\left(t_{(3)}=7.42, p=0.0051\right.$, Fig. $\left.1 C\right)$. Importantly, this initial experiment demonstrates that MF stimulation evokes beam-like responses in vivo, in contrast to previous results in the isolated guinea pig cerebellum (Cohen and Yarom, 1998; Rokni et al., 2007) but in agreement with an in vitro autofluorescence optical imaging study (Coutinho et al., 2004).

\section{NMDA activation of GCs evokes a beam-like response}

To obtain greater target selectivity than that afforded by electrical stimulation and to confirm the initial results showing beam-like activity in response to MF-PF-PC circuit activation, we used a pharmacological approach to activate GCs. We microinjected NMDA $(1.20 \pm 0.20 \mathrm{nl}, 500 \mu \mathrm{M})$ and its coagonist, glycine (10 $\mu \mathrm{M})$, into the cerebellar cortex bathed in a $0 \mathrm{Mg}^{2+}$ Ringer's solution. NMDA receptors are expressed on GCs and account for $\sim 30 \%$ of the excitatory response to MF input (D'Angelo et al., 1995). Conversely, adult mice do not have functioning NMDA 
receptors on PFs (Shin and Linden, 2005; Piochon et al., 2007; Lonchamp et al., 2012), although these receptors are expressed on PCs (Piochon et al., 2007; Renzi et al., 2007), suggesting that the NMDA will primarily activate GC dendrites and a patch of PCs and/or interneurons in the immediate vicinity of the injection. However, local activation of PCs and/or interneurons will not generate a beam-like response. NMDA/glycine microinjection evokes a beam-like activation pattern, with the largest amplitude responses evoked by injections within the GC layer between 200 and $350 \mu \mathrm{m}$ below the cortical surface (Fig. 2A,C). Also, a patch-like region of activation occurs above the site of injection. The $\Delta \mathrm{F} / \mathrm{F}$ responses evoked by NMDA/glycine for the beam region were $0.36 \pm 0.22 \%$ at $50-150$ $\mu \mathrm{m}, 0.75 \pm 0.41 \%$ at $200-350 \mu \mathrm{m}$, and $0.02 \pm 0.17 \%$ at $400-500 \mu \mathrm{m}$ (Fig. $2 C$; $n=7$ mice). The greatest magnitude response occurred when NMDA/glycine was injected at the 200-350 $\mu \mathrm{m}$ depth range, and the responses were significantly different at each depth $\left(F_{(15,186)}=\right.$ 24.55, $p<0.0001$ followed by post hoc test). The response amplitudes $(\Delta \mathrm{F} / \mathrm{F})$ in the central region were $0.61 \pm 0.41 \%$ at $50-150 \mu \mathrm{m}, 0.69 \pm 0.50 \%$ at $200-350$ $\mu \mathrm{m}$, and $0.11 \pm 0.20 \%$ at $400-500 \mu \mathrm{m}$. The largest amplitude responses occurred at both the $50-150 \mu \mathrm{m}$ and $200-350 \mu \mathrm{m}$ ranges $\left(F_{(15,186)}=32.37, p<0.0001\right.$ followed by post hoc test). As noted, this is expected as the NMDA will activate neurons locally at the injection site in both the molecular and GC layers. The lack of a response at the greatest depths below the GC layer $(>400 \mu \mathrm{m})$ adds further support that the responses are evoked by GC activation. The smaller response amplitude at greater depths is consistent with the mouse GC layer being $250 \mu \mathrm{m}$ thick beneath the $\sim 190 \mu \mathrm{m}$ molecular and PC layers (Serinagaoglu et al., 2007; Oz et al., 2011). At the 50-150 and 200-350 $\mu \mathrm{m}$ ranges, the responses also had the largest ML/RC ratios: $4.01 \pm 2.58$ and $4.60 \pm 1.74$, respectively $\left(F_{(8,19)}=\right.$ 4.72, $p=0.0026$, followed by post hoc test, Fig. 2C).

To verify that the responses were NMDA receptor-mediated, in three mice NMDA injections were repeated at the depth (200$350 \mu \mathrm{m}$ ) evoking a maximal response in the $0 \mathrm{Mg}^{2+}$ Ringer's solution after reintroduction of $2 \mathrm{mM} \mathrm{Mg}^{2+}$ into the optical chamber bath (Fig. $2 B$ ). In the presence of $\mathrm{Mg}^{2+}$, the amplitude of the beam response was significantly reduced from $0.61 \pm$ $0.19 \%$ to $0.16 \pm 0.12 \%\left(t_{(2)}=4.50, p=0.045, n=3\right.$, Fig. $\left.2 D\right)$. Similarly, the central response was significantly reduced from $0.95 \pm 0.34 \%$ to $0.21 \pm 0.08 \%\left(t_{(2)}=4.84, p=0.040\right)$. In the presence of $2 \mathrm{mM} \mathrm{Mg}^{2+}$, the ML/RC ratio decreased markedly to $2.02 \pm 0.89$, which was significantly different from the ratio obtained by NMDA injections at $200-350 \mu \mathrm{m}\left(t_{(2)}=22.28, p=\right.$
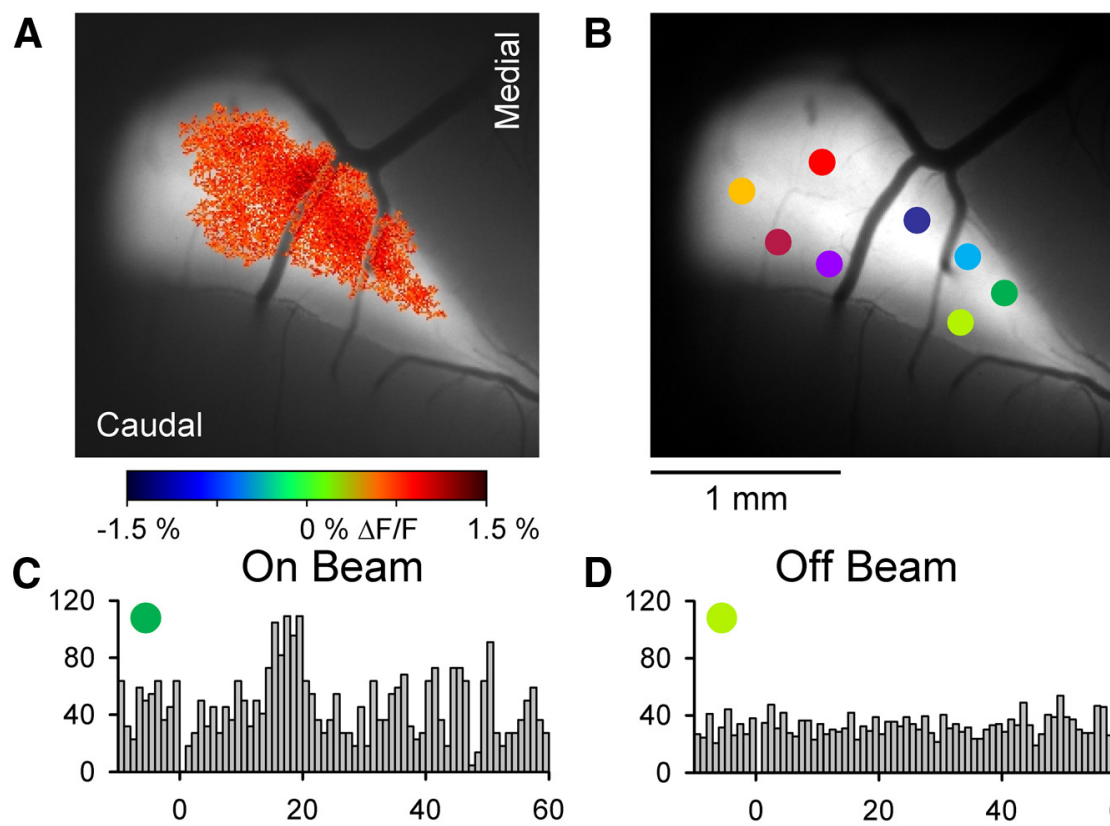

$1 \mathrm{~mm}$
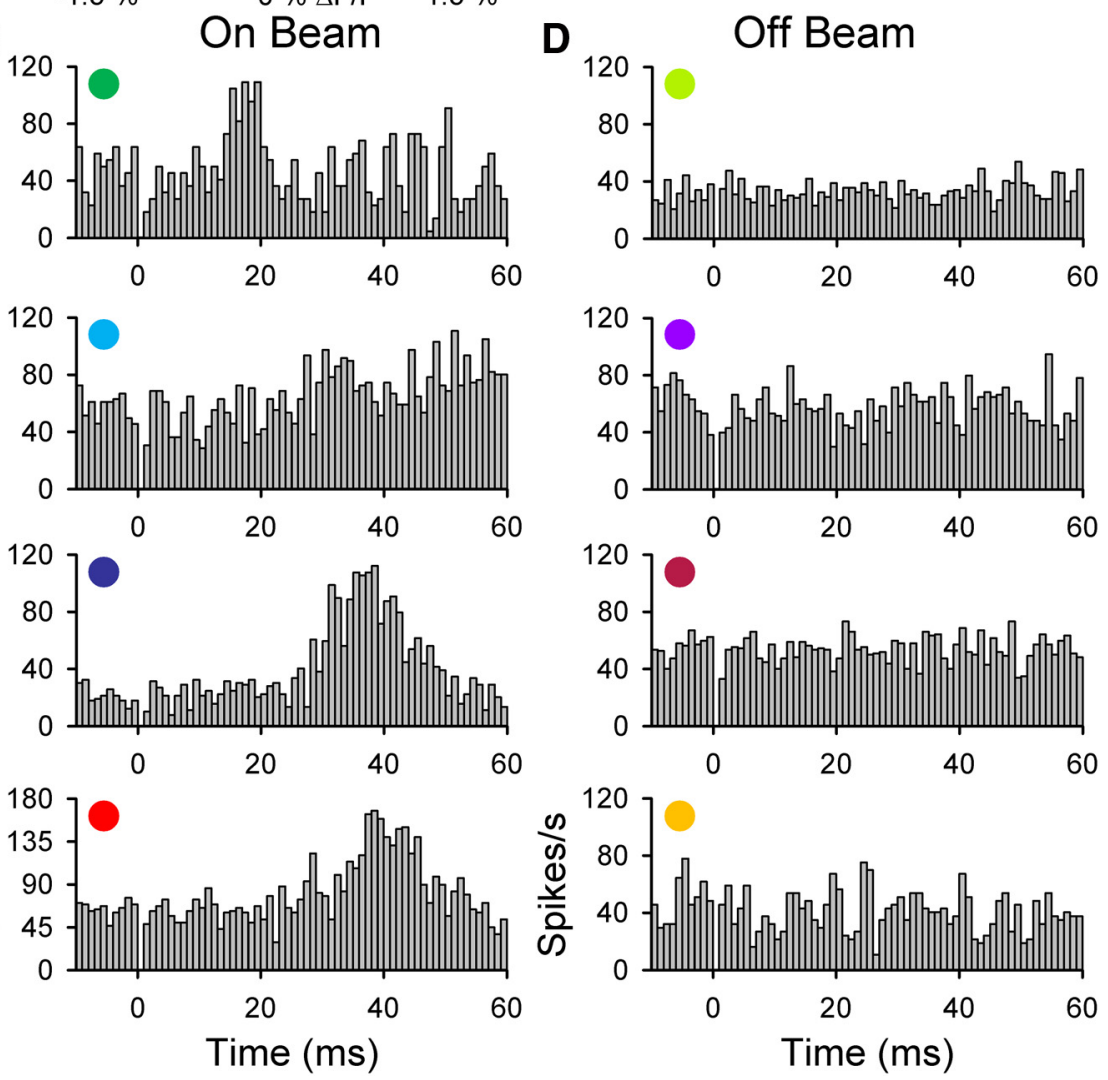

Figure 4. $\quad$ On and off beam PC simple spike responses in Crus I. $\boldsymbol{A}$, Example of the $\mathrm{Ca}^{2+}$ response defined by statistical thresholding (see Materials and Methods) evoked by ipsilateral forepaw stimulation overlaid on an image of the background fluorescence. $\boldsymbol{B}$, Recording locations for $\mathrm{PC}$ recorded within (On Beam) or outside (Off Beam) of the forelimb-evoked response region in A. C, D, Simple spike firing histograms corresponding to the PCs shown in $\boldsymbol{B}$. Histograms were constructed from 100 to 200 trials of $300 \mu \mathrm{s}, 20 \mathrm{~V}$ pulses. Stimulus onset at $t=0$ and $0 \mathrm{~ms}$ bin is blank because of the stimulus artifact.

0.0020, Fig. 2D). Therefore, electrical stimulation of MF afferents and glutamate and NMDA microinjection in the GC layer evoke beam-like responses, implying that strong stimulation of a group of MFs or GCs activate PFs that, in turn, activate PCs.

Peripheral stimulation evokes a beam-like response in Crus I Although the first two experiments demonstrate that MF and GC stimulation results in beam-like activation in vivo, it can be argued that neither stimulus is physiological (Bower, 2002, 2010). We estimate that the $150 \mu \mathrm{A}$ stimulation in the WM activated axons of passage within a volume of $4 \times 10^{-3} \mathrm{~mm}^{3}$, a sphere with a radius of $\sim 100 \mu \mathrm{m}$ (Ranck, 1975). Based on the volume $(\sim 1.2$ $\mathrm{nl})$ of the NMDA injections and the density of GC somata $(4 \times$ $10^{6}$ cells per $\mathrm{mm}^{3}$ ), we estimate that at least $4000 \mathrm{GCs}$ were 


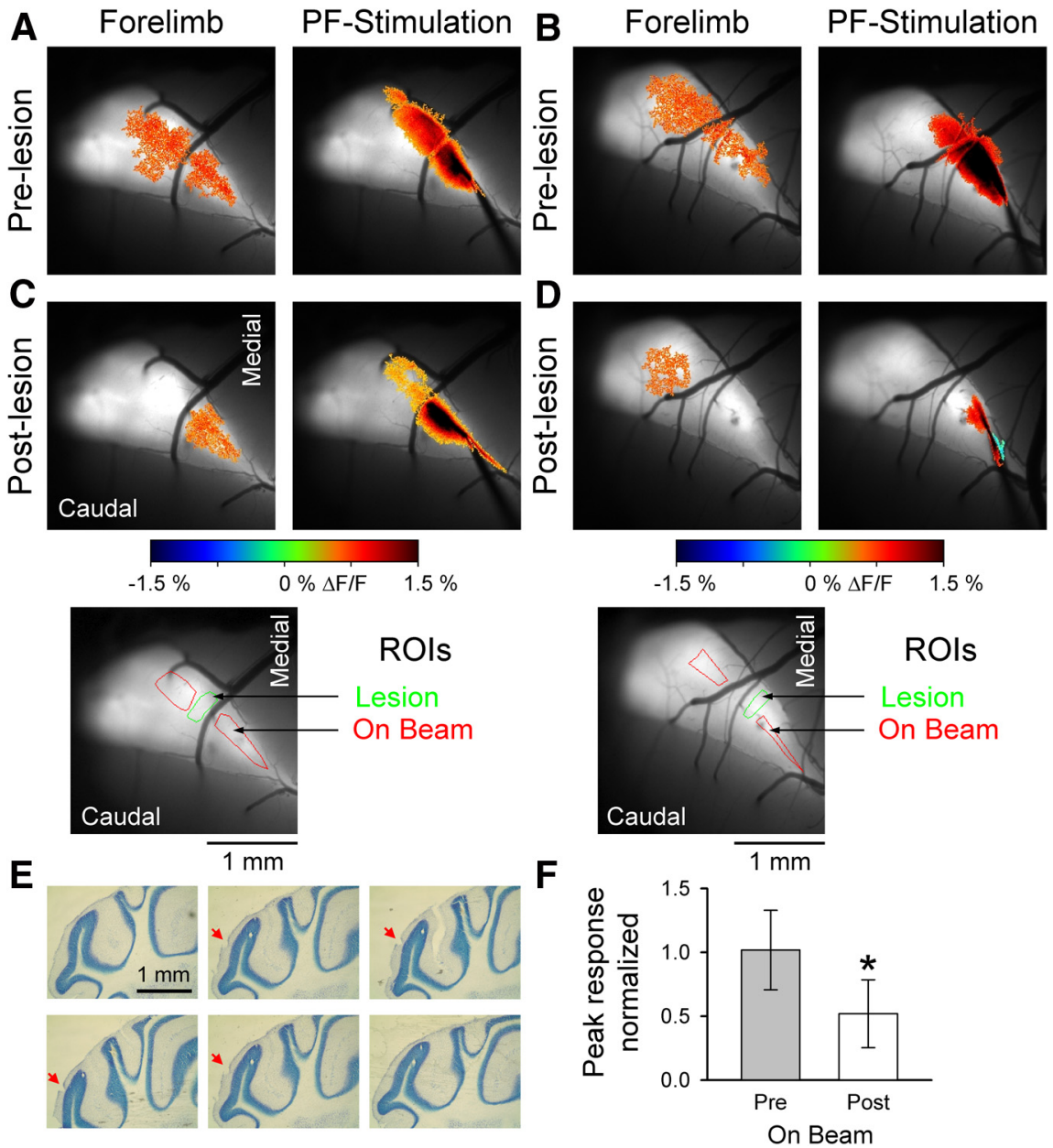

Figure 5. PFs contribute to the beam-like response in Crus I. $\boldsymbol{A}, \boldsymbol{B}$, Example images from two mice showing the fluorescence responses evoked by forelimb stimulation (left) or direct PF stimulation (right). C, D, After electrolytic lesioning of the molecular layer (inset below, green ROls), the peripherally evoked beam-like response (left) is reduced. Also, the response to direct PF stimulation is disrupted (right). Bottom images, The Rols used to quantify the On Beam response (red) and the location of the lesion (green). $\boldsymbol{E}$, Consecutive $40 \mu \mathrm{m}$ sections showing the lesion location and depth in the molecular layer (red arrow). $\boldsymbol{F}$, Normalized On Beam response to forelimb stimulation is significantly reduced after PF lesioning $(n=7$ mice). ${ }^{*} p<0.05$.

activated (Korbo et al., 1993). It remains to be determined whether peripherally driven MF inputs produce beam-like activation patterns. In response to ipsilateral forelimb stimulation, $\mathrm{Ca}^{2+}$ imaging reveals beam-like responses in Crus I (Fig. 3). Although some areas of patchy activation are also evident and suggestive of localized MF input, beam-like responses extend the entire length of the exposed folium. The ML/RC ratio of the responses evoked in Crus I by forelimb stimulation was $3.48 \pm 1.70$, a value consistent with a beam-like pattern. The population ratio was obtained from the 19 mice in which the responses in Crus I to forepaw stimulation were determined (Figs. 3, 4, and 5).

Although forelimb stimulation evokes beam-like patterns in Crus I, the contribution of PFs to the response remains unknown. This question was tested using two different approaches. First, single-unit activity was recorded in the molecular layer of Crus I inside and outside of the thresholded $\mathrm{Ca}^{2+}$ response area, as shown for an example experiment (Fig. 4A, B). For PCs recorded within the response region, simple spike activity increases significantly to the forelimb stimulation (Fig. 4C). Conversely, simple spike discharge for PCs recorded outside of the region is not modulated (Fig. 4D). In seven mice, 108 PCs and 28 unidentified neurons were recorded. The simple spike firing of 59\% ( 42 of 70) of the PCs recorded within the beam-like response region responded to the peripheral stimulus, whereas only $3 \%$ (1 of 38) of the PCs outside of the region were significantly modulated. These results are consistent with our previous studies that $\sim 90 \%$ of the flavoprotein signal is the result of postsynaptic activation (Wang et al., 2009, 2011; Reinert et al., 2011). The simple spike responses within the beam-like response regions had a latency of $27.7 \pm 5.0 \mathrm{~ms}$ and duration of $16.9 \pm 9.1 \mathrm{~ms}$. The latencies are comparable with those reported for forelimb stimulation in the rat (Holtzman et al., 2006). Similarly, $76 \%$ (16 of 21 ) of the unidentified cells recorded within the beam-like region and $0 \%$ of the unidentified cells recorded outside of the beam region exhibited a significant change in firing.

In the second approach to testing the $\mathrm{PF}$ contribution to the response, discrete lesions in the molecular layer were made to assess changes in the peripheral responses medial and lateral to the lesion. Figure 5 shows the results of two experiments. Forelimb stimulation evoked beam-like $\mathrm{Ca}^{2+}$ responses that parallel the rostral border of Crus I (Fig. $5 A, B$, left) similar to the responses evoked by $\mathrm{PF}$ stimulation (Fig. $5 A, B$, right). The electrolytic lesions ( $50 \mu \mathrm{A}, 1 \mathrm{~s}, 3-5$ locations) were made across the response defined by PF stimulation (Fig. 5C, D, green ROIs). After the lesioning, $\mathrm{PF}$ stimulation shows that the responses proximal to the lesion were relatively intact and either blocked or greatly reduced distal to the lesion (Fig. 5C, D, right). Importantly, the electrolytic lesions were discrete and limited to the molecular layer (Fig. $5 E$ ). The abrupt transection of the response to PF stimulation and the small lesions demonstrate that the damage to the cerebellar cortex was restricted. The extent of the lesion was further estimated in seven experiments by directly stimulating PFs on both the medial and lateral sides of the lesion and measuring the width of absent/decreased optical response. The average region of decreased responsiveness was $203 \pm 71 \mu \mathrm{m}$, suggesting that beyond the transection damage is limited and consistent with the histology (Fig. 5E). Further, these results establish that the PFs and cerebellar cortex are responsive and functioning on either side of the lesioned area.

Comparing the cerebellar responses to forelimb stimulation before and after lesioning shows the decrease in activation either lateral (Fig. 5C) or medial (Fig. 5D) to the lesion. The population data from seven mice show that the amplitude of the on-beam response to forelimb stimulation (Fig. $5 C, D$, red ROIs) is significantly reduced to $52 \pm 26 \%$ of the baseline response after the lesioning (Fig. $5 F ; t_{(6)}=7.28, p=0.0003$ ). Therefore, PFs contribute to the beam-like responses in Crus I. 


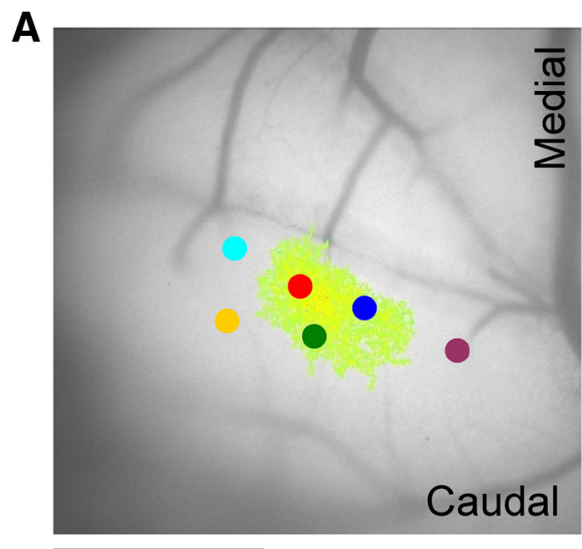

$1 \mathrm{~mm}$

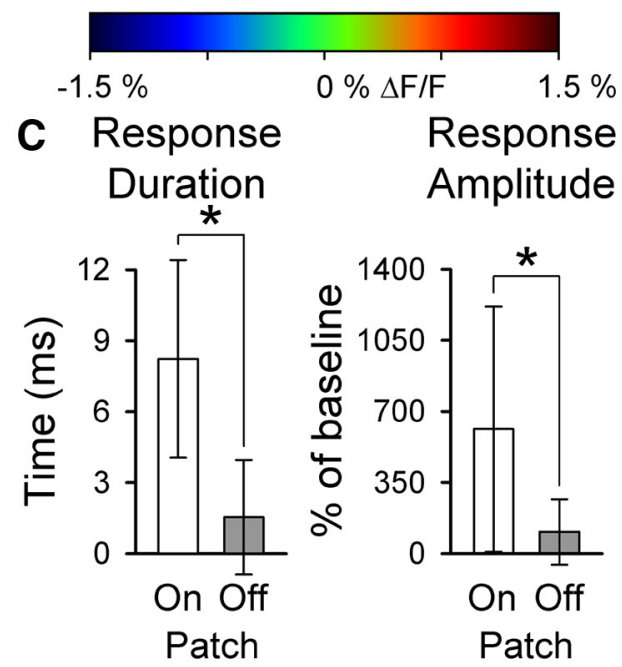

B
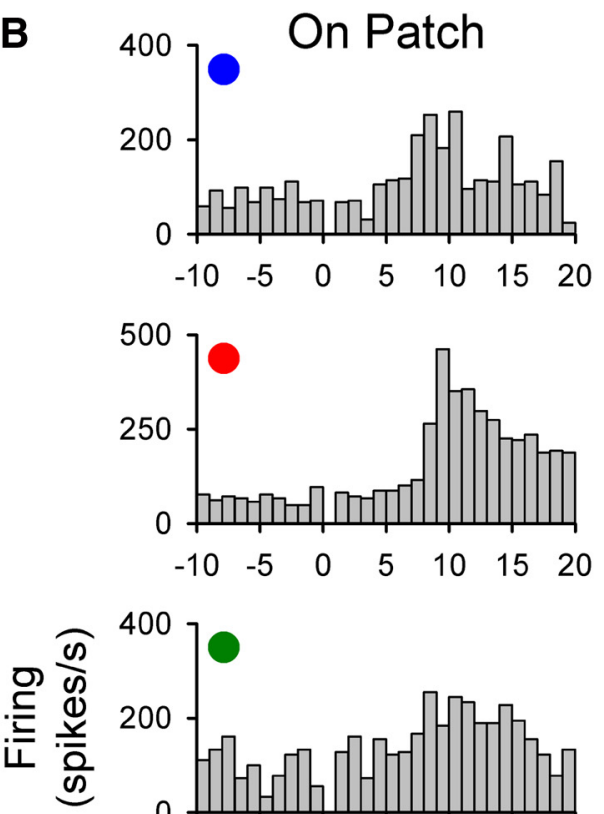

$\mathrm{D}$
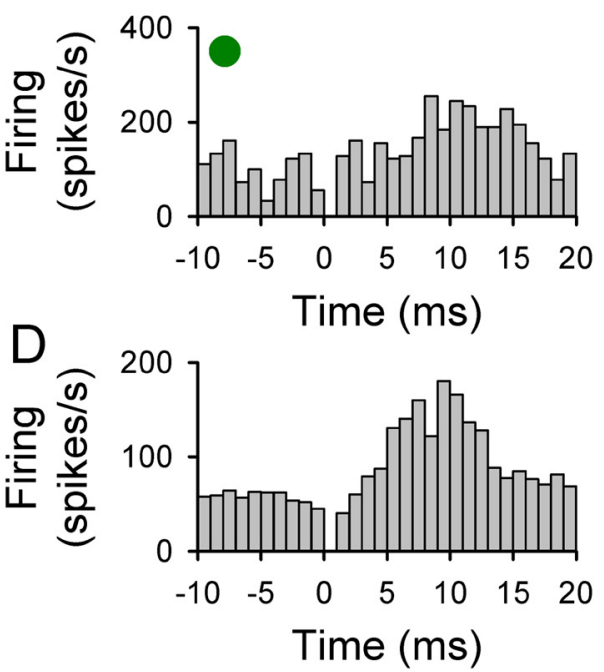
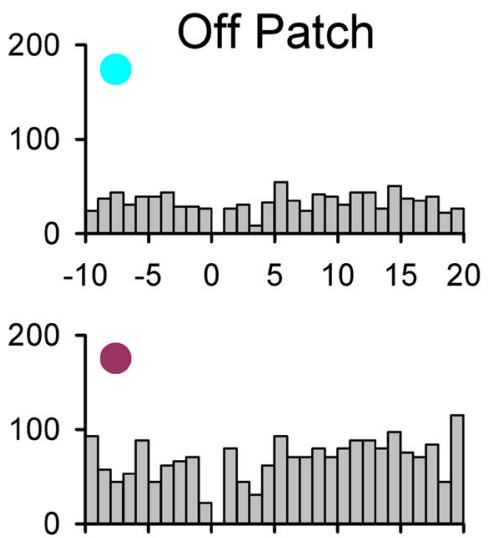

$\begin{array}{lllllll}-10 & -5 & 0 & 5 & 10 & 15 & 20\end{array}$
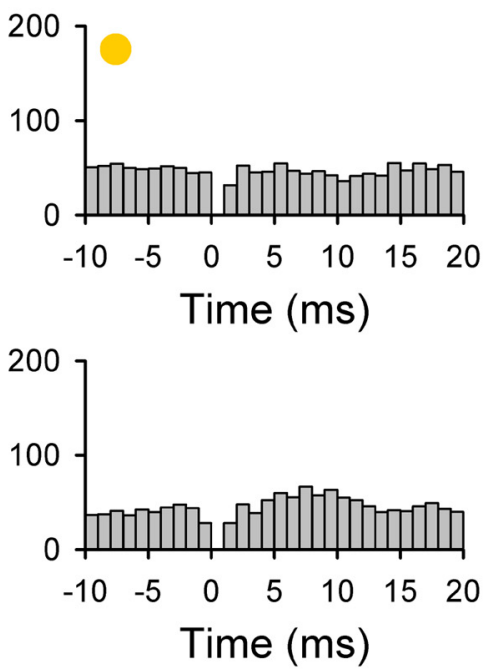

Figure 6. Spatial relation between flavoprotein and PC simple spike responses to peripheral stimulation in Crus II. $\boldsymbol{A}$, Ipsilateral vibrissal pad stimulation evokes patch-like increase in fluorescence that was defined by the statistical thresholding. Also shown are the recording locations (colored circles) of PCs relative to the optical response (On Patch vs Off Patch). $\boldsymbol{B}$, Simple spike histograms for the On Patch (left) and Off Patch (right) PCs shown in A. Each histogram was generated from 100 vibrissal stimuli. Other conventions as in Figure 4. $\boldsymbol{C}$, Duration and amplitude (mean \pm SD) of the significant simple spike modulation for the population of $80 \mathrm{PCs}$ recorded within and outside of the response region ( $n=8$ animals). $D$, Population histograms of simple spike firing for the 80 PCs recorded On Patch (left) and Off Patch (right) of the statistically defined optical response.

\section{Optical and single-cell responses to peripheral stimulation in} Crus II

Numerous studies report that peripheral inputs primarily evoke patch-like activation in the cerebellar cortex, particularly in Crus II (Bower and Woolston, 1983; Santamaria et al., 2002). These findings are in conflict with the beam-like activation found for peripheral stimulation in Crus I described above. Indeed, stimulation of the ipsilateral C3 vibrissa evokes patch-like activation in Crus II as assessed by flavoprotein imaging (Gao et al., 2006). However, our initial study did not examine the responses of single cells to this peripheral input nor did it assess whether the flavoprotein imaging has the sensitivity to detect beam-like activity. Therefore, the next experiment combined monitoring the responses to vibrissal stimulation with both flavoprotein imaging and single-cell recordings restricted to the molecular layer of Crus II within and outside of the response area. Both PCs and unidentified cells were recorded. As demonstrated previously (Gao et al., 2006), the flavoprotein responses to vibrissal stimulation are patch-like (Fig. $6 \mathrm{~A}$ ). Similar patch-like responses are found with $\mathrm{Ca}^{2+}$ imaging (see Figs. 8,9 , and 10). The example data show that the PC simple spike responses are consistent with the optical responses. PCs recorded within the region of increased fluorescence $( \pm 2$ SD above background) respond with a significant increase in simple spike firing, and cells recorded outside of the region do not respond (Fig. 6A, B). The correspondence between the simple spike and optical responses is also evident in the averaged simple spike responses for the $80 \mathrm{PCs}$ recorded within or outside of the optical responses (Fig. 6D). Of the 33 PCs recorded within the region of increased flavoprotein fluorescence, the simple spike firing of 30 (91\%) was modulated significantly by vibrissal stimulation. Of the $47 \mathrm{PCs}$ recorded outside the optical response region, the discharge of only 7 (15\%) was modulated significantly. None of the PCs responded with an increase in complex spike discharge. Similar to PCs, the firing of 22 (96\%) of the 23 unidentified cells located within the flavoprotein response region was significantly modulated by vibrissal stimulation. The firing of only $2(17 \%)$ of the unidentified cells recorded outside the border was modulated. Both the simple spike response duration and response amplitude are greater for PCs recorded within versus outside of the optical response (Fig. $6 \mathrm{C}$ ). The simple spike responses within the region of increased fluorescence have a latency of $9.8 \pm 1.5 \mathrm{~ms}$ and duration of $10.2 \pm 5.5 \mathrm{~ms}$. The unidentified cells recorded within the response region exhibit a similar latency of $10.1 \pm 2.5 \mathrm{~ms}$ and duration of $10.0 \pm 5.3 \mathrm{~ms}$.

We also tested whether there was a correlation between the firing rate change and the change in flavoprotein fluorescence. The correlation coefficient $(\rho)$ between the change in firing rela- 


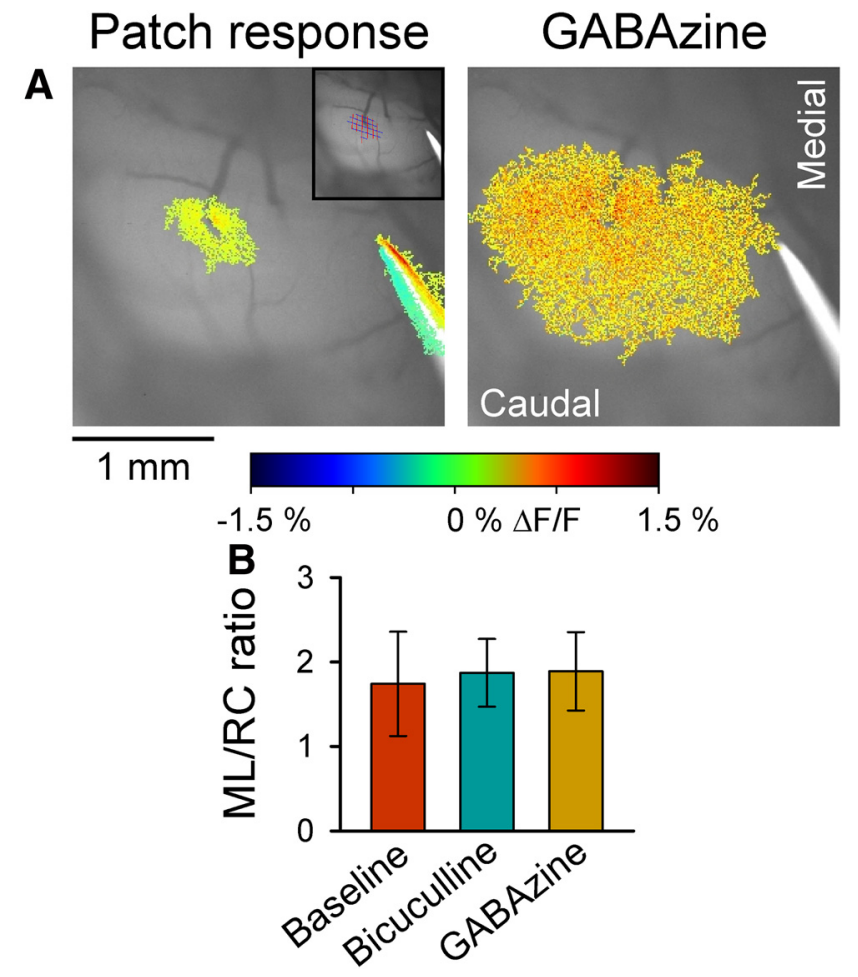

Figure 7. Blocking molecular layer inhibition does not result in beam-like responses. $\boldsymbol{A}$, Left, The patch-like response in Crus II to stimulation of the ipsilateral vibrissal pad. Top right inset, Thresholded response region covered by grid used to measure the $R C$ and $M L$ extent of the response. Statistical thresholded flavoprotein response is superimposed on the background fluorescence. Right, Application of GABAzine (SR-95531, $200 \mu \mathrm{m}$ ) increases the amplitude and area of the response but does not result in beam-like activation. Also shown in both images is the PF-stimulating electrode used in all experiments to test the integrity of the cerebellar cortex. $B$, Summary data of the ratio of the extent of the response in the ML and RC directions before (baseline) and after application of the $\mathrm{GABA}_{\mathrm{A}}$ antagonists, $200 \mu \mathrm{M}$ GABAzine or $100 \mu \mathrm{M}$ bicuculline ( $n=9$ mice).

tive to baseline and the $\Delta \mathrm{F} / \mathrm{F}$ at the corresponding recording location was determined for all 115 cells across eight animals. The correlation coefficient was 0.57 and provides further evidence that the flavoprotein signal reflects the underlying neuronal activity. Therefore, vibrissal stimulation evokes MF input into Crus II in a patch-like pattern, whether assessed by single-cell recordings or flavoprotein imaging, with no evidence of a beam-like response.

\section{Molecular layer inhibition does not suppress the beam-like response}

The next experiments addressed possible mechanisms for the beam-like responses in Crus I versus the patch-like responses in Crus II. It was hypothesized that molecular layer inhibitory interneurons control the geometry of the PCs activated by PFs and produce the patch-like responses (Bower, 2002; Santamaria et al., 2002; Santamaria et al., 2007; Bower, 2010). Application of $\mathrm{GABA}_{\mathrm{A}}$ antagonists was reported to result in beam-like responses in PCs (Santamaria et al., 2007). We reexamined this hypothesis monitoring the flavoprotein responses in Crus II evoked by stimulation of the ipsilateral C3 vibrissa under baseline conditions and in the presence of $\mathrm{GABA}_{\mathrm{A}}$ receptor antagonists $(200 \mu \mathrm{M}$ GABAzine or $100 \mu \mathrm{M}$ bicuculline) (Gao et al., 2006). If molecular layer inhibition underlies the patch-like geometry of cerebellar cortical activation to GC input, blocking the action of GABAergic interneurons is expected to convert the patch-like response into a more beam-like response (Santamaria et al., 2007). As shown in the example experiments, the application of $\mathrm{GABA}_{\mathrm{A}}$ receptor antagonists increases the amplitude and overall area of activation but does not result in conversion to a beam-like response (Fig. $7 A$ ). Furthermore, we measured the ML/RC ratios; whether the response becomes more beam-like with blocking GABAergic transmission, the ratio should increase. However, the ML/RC ratios were $1.74 \pm 0.62$ for the baseline, $1.87 \pm 0.40$ upon bicuculline application $(n=6$ mice $)$, and $1.89 \pm 0.46$ with GABAzine ( $n=3$ mice). The ratios were not significantly different for either antagonist $(p>0.05$ for both drugs, paired Student's $t$ test, Fig. $7 B)$. These results are in agreement with voltage-sensitive dyeimaging studies in vitro in which blocking $\mathrm{GABA}_{\mathrm{A}}$ receptors failed to generate beam-like responses to MF stimulation (Rokni et al., 2007). Therefore, although molecular layer inhibition controls the amplitude and spatial extent of the responses (Gao et al., 2006), it does not prevent beam-like activation in vivo.

\section{Role of excitatory amino acid transporters in the spatial pattern of the responses to peripheral input}

Unresolved is why peripheral inputs evoke beam-like responses in Crus I (Figs. 3, 4, and 5) and patch-like activation in Crus II (Figs. 6 and 7). Because molecular layer inhibition does not appear to be responsible, we hypothesized that the differential distribution of EAAT4 on PCs in Crus I and Crus II plays a role (Gincel et al., 2007). EAAT4 is the predominant glutamate transporter on PCs, is PC-specific, and is expressed in parasagittal bands of zebrin-positive PCs in Crus II (Nagao et al., 1997; Dehnes et al., 1998; Gincel et al., 2007). The parasagittal distribution of EAAT4s is known to differentially modulate PC responses to both PF and climbing fiber inputs (Wadiche and Jahr, 2005; Paukert et al., 2010; Tsai et al., 2012). In contrast, EAAT4 is expressed uniformly in Crus I.

To test this hypothesis, the first experiment used a reporter mouse that expresses GFP under the control of the EAAT4 promoter (Gincel et al., 2007). In Crus II, vibrissal stimulation evokes patch-like increases in $\mathrm{Ca}^{2+}$ fluorescence similar to those observed with flavoprotein imaging (compare Figs. 7 and 8). As shown for the two example experiments, the $\mathrm{Ca}^{2+}$-mediated responses to vibrissal stimulation are centered between the parasagittal zones with the higher expression levels of EAAT4 (Fig. $8 A$ ). Also, there is a lack of a parasagittal distribution of EAAT4 in Crus I (Gincel et al., 2007). To quantify the spatial relationship between the optical responses and the distribution of EAAT4, a rectangular ROI ( $800 \mu \mathrm{m}$ along the mediolateral axis of the folium and $10 \mu \mathrm{m}$ along the rostrocaudal axis of the folium) was defined that encompassed both the responsive and nonresponsive regions. The fluorescence change along the ROI was determined for both the $\mathrm{Ca}^{2+}$ responses and the background fluorescence of EAAT4 expression, and the correlation coefficient between these two profiles was computed. The fluorescence profiles for the two example experiments show the inverse relationship between EAAT4 expression and the responses to $\mathrm{C} 3$ vibrissa stimulation (Fig. $8 B$ ) and the negative correlation coefficient $(\rho=-0.43$ and $\rho=-0.91, p<0.0001)$. In each of the six mice studied, a significant inverse relationship exists between the regions responding to the peripheral stimulus and EAAT4 expression (average $\rho=-0.70$, range -0.43 to -0.91 ).

We reasoned that, if the higher level of EAAT4 in the parasagittal zones reduces the responses of PCs to MF inputs, then blocking EAATs should convert the patch-like activation of Crus II into a beam-like response. Therefore, the EAAT blocker TBOA was applied to the Ringer's solution in the optical chamber 
(Dehnes et al., 1998; Shimamoto et al., 1998). In both FVB (Fig. 9A) and EAAT4 reporter mice (Fig. 9B), vibrissal stimulation evokes the typical patch-like responses in Crus II. Application of TBOA increases the response amplitude and extent of the patch components but also results in a beam-like profile. For both examples in the presence of TBOA, there are two patches of increased fluorescence embedded in a beam-like response that extends the length of the folium. The conversion to a beam-like profile was observed in all 12 mice tested (10 FVB and 2 EAAT4) and quantified using the analysis described for evaluating the effect of the GABAergic antagonists (Fig. 7). The $\mathrm{ML} / \mathrm{RC}$ ratio was $1.46 \pm 0.64$ for the patch-like response and increased significantly to $3.24 \pm 1.44$ upon application of TBOA $\left(t_{(11)}=-4.73, p=\right.$ 0.0006; Fig. 9C).

If the beam-like response in the presence of TBOA is driven by a general increase of excitability at the level of the granular layer, local inhibition of MF-GC synaptic transmission should affect a correspondingly local region of the beam-like response. Conversely, if the TBOA is acting at the level of the PF-PC synapse, local block of MF-GC synaptic transmission should decrease the activation along the beam-like response resulting from a reduction in PF activation. To test this hypothesis, the AMPA and NMDA iGluR antagonists (100 $\mu \mathrm{M}$ DNQX and $250 \mu \mathrm{M} \mathrm{APV}, 5.95 \pm 2.37 \mathrm{nl}$ ) were injected into the granular layer (depth of $250 \mu \mathrm{m}$ ) with the TBOA application, targeting the patch region of increased fluorescence evoked by vibrissal stimulation. Similar to Figure 9, the two examples in Figure 10A, $B$ demonstrate the conversion of the peripherally evoked patch-like response to a beam-like profile by TBOA $(300 \mu \mathrm{M})$. With injection of the iGluR antagonists, the beam-like responses to vibrissal stimulation are reduced, both medially and laterally. For the six mice tested, the evoked fluorescence changes were quantified as for the WM stimulation and NMDA injection experiments (Figs. 1 and 2). For the beam region, the average $\Delta \mathrm{F} / \mathrm{F}$ was $0.21 \pm 0.09 \%$ for vibrissal stimulation alone, $0.71 \pm 0.31 \%$ in the presence of TBOA, and $0.45 \pm 26 \%$ for microinjection of iGluR antagonists in the presence of TBOA $\left(F_{(17,398)}=88.6, p<0.0001\right.$ followed by post hoc test). Similarly, the $\Delta \mathrm{F} / \mathrm{F}$ response for the central region was $0.38 \pm 0.16 \%$ for vibrissal stimulation, $1.18 \pm 0.59 \%$ upon bath application of TBOA, and $0.52 \pm 0.48 \%$ for microinjection of iGluR antagonists with TBOA $\left(F_{(17,398)}=190.7, p<0.0001\right.$ followed by post hoc test). The ML/RC ratio was $1.02 \pm 0.17$ for the patch-like response, increased significantly to $2.18 \pm 0.63$ $\left(t_{(10)}=-4.32, p=0.0015\right)$ upon application of TBOA, and decreased to $0.86 \pm 0.55\left(t_{(10)}=3.85, p=0.0032\right)$ with injection of the iGluR antagonists. Therefore, a focal reduction in GC activity results in decreased activation along the beam and converts a beam-like response into a patch-like response, consistent with PF-mediated activation along the transverse axis of Crus II.

The $\sim 6.0 \mathrm{nl}$ injection volume of DNQX/APV is a $180-\mu \mathrm{m}-$ diameter sphere. To assess the spatial extent of the action of the injected iGluR antagonists, a control experiment was performed. Two beams were evoked by direct PF stimulation in Crus II (see example in Fig. 10D), and the iGluR antagonists were injected at a depth of $\sim 250 \mu \mathrm{m}$ below the cerebellar surface between the beams. We reasoned that the extent to which the response to PF stimulation in the molecular layer was altered would provide an estimate of the spread of the iGluR antagonists. As shown in the example (Fig. 10D), injecting iGluR antagonists into the granular layer had no obvious effect on the response to PF stimulation, demonstrating that the spread into the molecular layer, and therefore, into the GC layer, is limited. The $\Delta \mathrm{F} / \mathrm{F}$ responses were quantified for three mice using the same approach as the WM stimulation experiment (Fig. 1). The center ROI was placed directly over the injection, and the beam ROIs were measured medial and lateral to the injection site. The $\Delta \mathrm{F} / \mathrm{F}$ response for the beam region was $0.96 \pm 0.12 \%$ for the baseline and $0.97 \pm 0.11 \%$ with injection of the iGluR antagonists $\left(t_{(95)}=0.82\right.$, $p=0.4149$; Fig. $10 E)$. The $\Delta \mathrm{F} / \mathrm{F}$ response for the central region was $1.44 \pm 0.29 \%$ for the baseline and $1.36 \pm 0.21 \%$ with injection of the iGluR antagonists $\left(t_{(95)}=1.66, p=0.1005\right.$; Fig. $\left.10 E\right)$. This experiment demonstrates that microinjection of iGluR antagonists into the granular layer acts to locally block the MF-GC synapse. The iGluR antagonists do not diffuse sufficiently into the molecular layer to affect PF-PC synaptic transmission. Therefore, the results obtained from the EAAT4 reporter mice and TBOA experiments strongly suggest that EAATs, including EAAT4s on PCs, are involved in modulating the spatial pattern of the response to MF inputs in the cerebellar cortex.

\section{Discussion}

The first major finding is that MF or GC stimulation activates beam-like responses in the cerebellar cortex in vivo. There is also a large amplitude response directly above the site of MF or GC stimulation, consistent with the GC ascending limb axons exerting a strong influence on PCs. With electrical stimulation, there remains some possibility of direct PF activation, for example, spread of current along the electrode-tissue interface. Importantly, microinjection of NMDA into the granular layer evokes a 


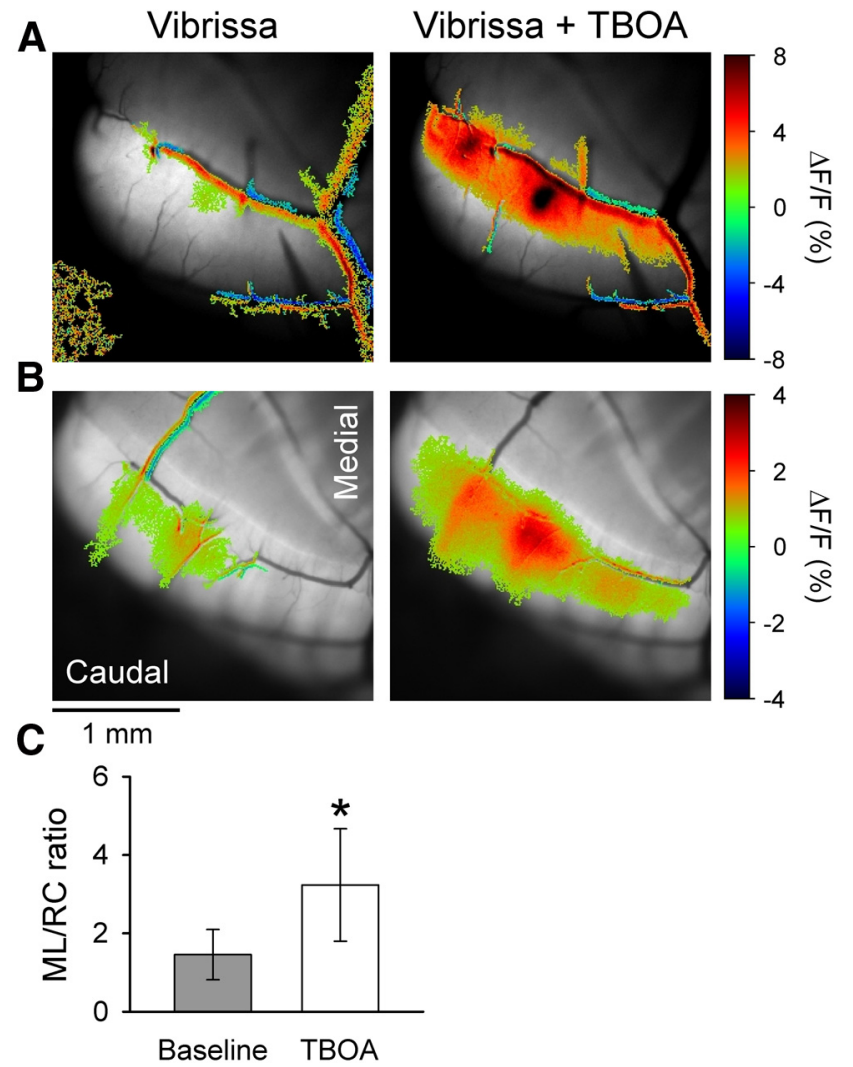

Figure 9. Blocking EAATs converts the patch-like response in Crus II to a beam-like response. $A$, Statistically thresholded image of the $\mathrm{Ca}^{2+}$ response in Crus II to ipsilateral vibrissal stimulation (10-20 V, $300 \mu$ s pulses at $100 \mathrm{~Hz}$ for $50-100 \mathrm{~ms}$ ) before (Vibrissa) and upon bath application of $300 \mu \mathrm{m}$ TBOA in an FVB mouse (Vibrissa + TBOA). There is increased fluorescence response on or surrounding several blood vessels. This reflects the increased blood flow that accompanies activation of the cerebellar cortex (Mathiesen et al., 1998; Yang et al., 1999). Blood vessel-related activation was commonly observed. $\boldsymbol{B}$, Same experiment as in $\boldsymbol{A}$ in an EAAT4 reporter mouse. $C$, Ratio of ML to RC dimensions of the evoked responses in the baseline condition (gray) and in the presence of TBOA (white) based on $10 \mathrm{FVB}$ and 2 EAAT4 mice. ${ }^{*} p<0.05$.

postsynaptic beam-like response. Given the lack of functioning NMDA receptors on PFs in adult mice (Shin and Linden, 2005; Qiu and Knopfel, 2007; Piochon et al., 2010), NMDA provides a highly selective method of activating GCs without activating PFs directly. PCs and cerebellar interneurons express NMDA receptors (Bilak et al., 1995; Piochon et al., 2007; Renzi et al., 2007); however, activation by focal NMDA injection would result in a patch response and not the observed beam-like activation pattern.

To our knowledge, the observation that forelimb stimulation evokes beam-like responses in Crus I is the first optical imaging evidence for the beam hypothesis. Single-cell recordings confirm PC simple spike activation along the beam. Importantly, focal lesioning of PFs reduces the activation lateral and medial to the transection, strongly suggesting that PFs contribute to the transverse response. If the beam-like response was solely the result of GC ascending axons, the decrease would be limited to the lesion site.

\section{Molecular layer inhibition does not control beam-like responses}

The next major finding is that molecular layer inhibition does not prevent beam-like activation of PCs (Santamaria et al., 2007; Bower, 2010). Application of $\mathrm{GABA}_{\mathrm{A}}$ antagonists does not convert patch-like responses into beam-like responses, and instead the response amplitude and extent along both the mediolateral and rostrocaudal axes increases. Conversion of the patch-like response into a beam-like response by TBOA demonstrates that optical imaging has the sensitivity to detect such changes in the activation pattern (Figs. 9 and 10). The single-cell recordings establish that the flavoprotein autofluorescence accurately represents the spatial extent of the underlying neuronal responses. Possibly the flavoprotein imaging may have failed to detect beam-like responses in PCs consisting of very brief duration excitation followed by prolonged inhibition. However, this type of response is highly unlikely given that block of $\mathrm{GABA}_{\mathrm{A}}$ receptors increases the duration of the excitation and blocks the inhibition (Jaeger and Bower, 1994; Bao et al., 2010). Therefore, present and previous results fail to support the hypothesis that molecular layer inhibition prevents beam-like responses.

\section{Role of parasagittal zones and glutamate extracellular concentration in response pattern}

The finding of patch-like responses in Crus II and beam-like responses in Crus I raises the question of the mechanism underlying the regional differences. Intriguingly, a recent study examining whisker inputs into Crus I and Crus II observed a similar phenomenon (Bosman et al., 2010). Comodulation in the simple spike discharge occurs in transversally located pairs of PCs in Crus I but not in Crus II. One likely explanation is the known differences in parasagittal zonation. Crus II has zebrin-positive and -negative zones that reflect differential expression of a host of molecules on PCs (Apps and Hawkes, 2009), many of which control PC excitability and plasticity (Brasnjo and Otis, 2001; Wadiche and Jahr, 2005; Gao et al., 2006; Paukert et al., 2010; Wang et al., 2011). However, Crus I lacks this parasagittal zonation (Figs. 8 and 9) (Sillitoe et al., 2003; Sarna et al., 2006).

One possible contributor to the patch-like responses is EAAT4. The level of EAAT4 expression on PCs is inversely correlated with glutamate concentration and extrasynaptic GluR activation (Tsai et al., 2012). As we show, the responses to peripheral input in Crus II are inversely related to EAAT4 expression. There are a number of possible explanations. However, differential release of glutamate does not appear to contribute as release is similar in regions with low and high EAAT4 levels (Tsai et al., 2012). We propose that the low levels of EAAT4 play a role in generating the patch-like responses. Another possibility is that the MF projections mediating the vibrissae response preferentially terminate between zebrin II parasagittal bands and contribute to the patch-like activation. As recently reviewed (Apps and Hawkes, 2009), MFs show some, but not perfect, alignment with the overlying zebrin banding pattern or longitudinal zones (Ji and Hawkes, 1994; Wu et al., 1999; Voogd et al., 2003; Pijpers et al., 2006). Nor is there evidence that MF inputs selectively innervate regions of low EAAT4 expression and sparingly innervate regions of high EAAT4. For example, granular layer responses to peripheral and central inputs show activation throughout Crus I and Crus II (Shambes et al., 1978; Kassel, 1980; Kassel et al., 1984). Similar maps in Crus II and lobule IX show granular layer responses to the same input that extend across overlaying zebrinpositive and -negative zones (Chockkan and Hawkes, 1994; Hallem et al., 1999). Therefore, it is unlikely the differential responses in relation to EAAT4 zonation are solely the result of variation in the strength of the MF projections. There are other mechanisms that could contribute to patch-like versus beam-like responses (e.g., the recently described differential transmitter release probability at PF-PC synapses during GC high-frequency bursts) (van Beugen et al., 2013). Still, the present results show that PFs are 

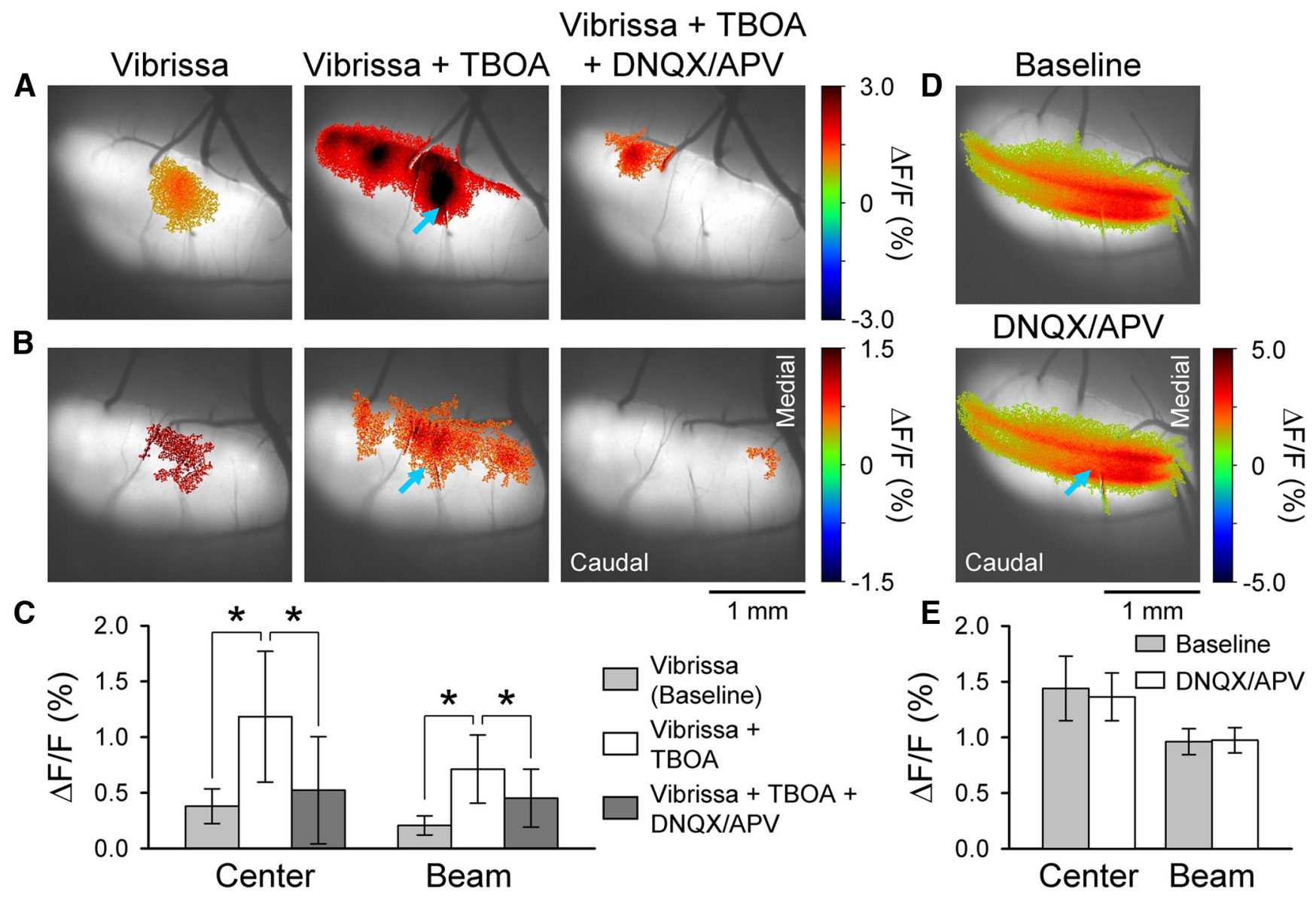

Figure 10. Microinjection of glutamate receptor antagonists into the granular layer disrupts beam-like response in Crus II. $\boldsymbol{A}, \boldsymbol{B}$, Statistically thresholded images from two mice of the Ca ${ }^{2+}$ response evoked by ipsilateral vibrissal pad stimulation (Vibrissa), with bath application of $300 \mu \mathrm{M}$ TBOA (Vibrissa + TBOA), and with microinjection of iGluR antagonists (100 $\mu \mathrm{m}$ DNQX and $250 \mu \mathrm{m}$ APV, $5.95 \pm 2.37 \mathrm{nl}$ ) into the granular layer (depth of $\sim 250 \mu \mathrm{m}$ ). Middle, Blue arrow indicates the injection site. In both examples, focal injection of iGluR antagonists into the granular layer reduces the beam-like response in the presence of TBOA. The PF-stimulating electrode is evident in the experiment shown in $\boldsymbol{A}$. Also, blood vessel-related increases in fluorescence are present in both $\boldsymbol{A}$ and $\boldsymbol{B}$ (Fig. 9). C, Summary data ( $n=6$ mice) for the center and beam response components for the baseline with TBOA alone and TBOA with microinjection of GluR antagonists. ${ }^{*} p<0.05$. $\boldsymbol{D}$, Statistically thresholded images of the $\mathrm{Ca}^{2+}$ response in Crus Il evoked by direct PF stimulation with two electrodes before (Baseline) and after microinjection of iGluR antagonists (DNQX/APV) at a depth of 250 $\mu \mathrm{m}$ (blue arrow). $\boldsymbol{E}$, Summary data ( $n=3$ mice) for the center and beam responses for the baseline and DNQX/APV injection.

activated and glutamate clearance plays an important role in whether PCs are activated in patches or beams.

The TBOA experiments support the interpretation that EAATs shape the response pattern, with foci of activation that become beam-like in the presence of TBOA (Figs. 9 and 10). What the TBOA results show is that, by increasing extracellular glutamate concentration, PC excitability increases and the PF contribution becomes apparent. The change to a beam-like pattern is unlikely to reflect a generalized increase in excitability, as $\mathrm{GABA}_{\mathrm{A}}$ receptor antagonists increase excitability without producing a beam (Fig. 7). We hypothesized that the patch-like regions are a major source of the activated PFs responsible for the beam-like response. The finding that focal injection of iGluR antagonists into the granular layer reduces the beam-like responses strongly supports this hypothesis.

Direct PF, MF, or GC stimulation evokes beam-like responses in Crus II that may seem at odds with the patch-like responses to peripheral stimulation. However, parasagittal differences in EAAT4 levels do not affect electrically evoked postsynaptic responses on PC spines (Tsai et al., 2012), accounting for the beamlike responses to direct electrical or NMDA stimulation. We also suggest that PF, MF, or GC stimulation produces a larger and more synchronized PF input that can overcome local mecha- nisms controlling excitability. In contrast, peripheral stimulation produces smaller amplitude and less synchronous activation of MFs, and in turn GCs, allowing EAAT4 to have a greater role in shaping the spatial pattern of the responses. Although we can only speculate on functional implications, the results suggest differential requirements for processing of PF inputs, with greater responsiveness in zones expressing lower levels of EAAT4. A corollary is that the width of such processing zones is defined by EAAT4 expression levels. This is consistent with growing evidence that the parasagittal zones have differential physiological and functional properties (Apps and Hawkes, 2009). Clearly, additional studies are needed to determine whether the parasagittal distribution of EAAT4 on PCs has similar effects on the response patterns in different folia.

\section{Reconciling previous observations}

The present results explain some of the reported discrepancies on the response patterns in Crus I versus Crus II. Several studies supporting the radial hypothesis based their conclusions on patch-like PC responses to peripheral stimuli in Crus II (Bower and Woolston, 1983; Santamaria et al., 2007). There is also less evidence for PF-mediated synchrony in Crus II than in Crus I (Bosman et al., 2010; Wise et al., 2010). Furthermore, in the cat 
anterior lobe, responses to various stimuli occur along several millimeters of a folium (Yu et al., 1985; Garwicz and Andersson, 1992; Valle et al., 2008), and these folia have narrower and more widely spaced zebrin II zones (Sillitoe et al., 2003). Although we can only infer that the physiological responses in previous reports are related to EAAT4 expression levels, the evidence suggests the present findings generalize beyond Crus I and Crus II. The results do not necessarily explain why WM stimulation in the isolated cerebellum preparation primarily evoked patch-like responses (Cohen and Yarom, 1998; Rokni et al., 2007). An anatomical comparison is not possible as these earlier studies did not report the lobules evaluated. However, differences between the previous and present studies, including using an isolated preparation versus intact animal and voltage-sensitive dye versus $\mathrm{Ca}^{2+}$ imaging, respectively, likely explain the differences.

In conclusion, the present study demonstrates that, in response to peripheral inputs, PFs are activated and modulate PC activity as predicted by the beam hypothesis. However, the hypothesis also envisioned sequential activation along the PFs (Braitenberg and Atwood, 1958; Braitenberg, 1961; Braitenberg et al., 1997). Detecting sequential activity is problematic given that physiological inputs, particularly during behavior, produce complex patterns of MF inputs in space and time (Figs. 3, 8, and 9 ). The nonhomogeneous properties of the cerebellar cortex add to the complexity (Apps and Hawkes, 2009), and these factors are likely to obscure any hypothesized timing differences in PC activity along the PFs. The present findings also demonstrate that synapses along the GC ascending limb modulate PC activity. Both the beam and patch-like elements must be integrated into our understanding of cerebellar cortical function.

\section{References}

Apps R, Hawkes R (2009) Cerebellar cortical organization: a one-map hypothesis. Nat Rev Neurosci 10:670-681. CrossRef Medline

Bao J, Reim K, Sakaba T (2010) Target-dependent feedforward inhibition mediated by short-term synaptic plasticity in the cerebellum. J Neurosci 30:8171-8179. CrossRef Medline

Bell CC, Grimm RJ (1969) Discharge properties of Purkinje cells recorded on single and double microelectrodes. J Neurophysiol 32:1044-1055. Medline

Bilak SR, Bilak MM, Morest DK (1995) NMDA receptor expression in the mouse cerebellar cortex. Synapse 20:257-268. CrossRef Medline

Bosman LW, Koekkoek SK, Shapiro J, Rijken BF, Zandstra F, van der Ende B, Owens CB, Potters JW, de Gruijl JR, Ruigrok TJ, De Zeeuw CI (2010) Encoding of whisker input by cerebellar Purkinje cells. J Physiol 588: 3757-3783. CrossRef Medline

Bower JM (2002) The organization of cerebellar cortical circuitry revisited: implications for function. Ann N Y Acad Sci 978:135-155. CrossRef Medline

Bower JM (2010) Model-founded explorations of the roles of molecular layer inhibition in regulating Purkinje cell responses in cerebellar cortex: more trouble for the beam hypothesis. Front Cell Neurosci 4:27. CrossRef Medline

Bower JM, Woolston DC (1983) Congruence of spatial organization of tactile projections to granule cell and Purkinje cell layers of cerebellar hemispheres of the albino rat: vertical organization of cerebellar cortex. J Neurophysiol 49:745-766. Medline

Braitenberg V (1961) Functional interpretation of cerebellar histology. Nature 190:539-540. CrossRef

Braitenberg V, Atwood RP (1958) Morphological observations on the cerebellar cortex. J Comp Neurol 109:1-33. CrossRef Medline

Braitenberg V, Heck D, Sultan F (1997) The detection and generation of sequences as a key to cerebellar function: experiments and theory. Behav Brain Sci 20:229-245; discussion 245-277. CrossRef Medline

Brasnjo G, Otis TS (2001) Neuronal glutamate transporters control activation of postsynaptic metabotropic glutamate receptors and influence cerebellar long-term depression. Neuron 31:607-616. CrossRef Medline

Chen G, Hanson CL, Ebner TJ (1996) Functional parasagittal compart- ments in the rat cerebellar cortex: an in vivo optical imaging study using neutral red. J Neurophysiol 76:4169-4174. Medline

Chen G, Popa LS, Wang X, Gao W, Barnes J, Hendrix CM, Hess EJ, Ebner T] (2009) Low-frequency oscillations in the cerebellar cortex of the tottering mouse. J Neurophysiol 101:234-245. CrossRef Medline

Chockkan V, Hawkes R (1994) Functional and antigenic maps in the rat cerebellum: zebrin compartmentation and vibrissal receptive fields in lobule IXa. J Comp Neurol 345:33-45. CrossRef Medline

Cohen D, Yarom Y (1998) Patches of synchronized activity in the cerebellar cortex evoked by mossy-fiber stimulation: questioning the role of parallel fibers. Proc Natl Acad Sci U S A 95:15032-15036. CrossRef Medline

Coutinho V, Mutoh H, Knöpfel T (2004) Functional topology of the mossy fibre-granule cell-Purkinje cell system revealed by imaging of intrinsic fluorescence in mouse cerebellum. Eur J Neurosci 20:740-748. CrossRef Medline

D’Angelo E, De Filippi G, Rossi P, Taglietti V (1995) Synaptic excitation of individual rat cerebellar granule cells in situ: evidence for the role of NMDA receptors. J Physiol 484:397-413. Medline

Dehnes Y, Chaudhry FA, Ullensvang K, Lehre KP, Storm-Mathisen J, Danbolt NC (1998) The glutamate transporter EAAT4 in rat cerebellar Purkinje cells: a glutamate-gated chloride channel concentrated near the synapse in parts of the dendritic membrane facing astroglia. J Neurosci 18:3606-3619. Medline

De Zeeuw CI, Koekkoek SK, Wylie DR, Simpson JI (1997) Association between dendritic lamellar bodies and complex spike synchrony in the olivocerebellar system. J Neurophysiol 77:1747-1758. Medline

Ebner TJ, Bloedel JR (1981) Temporal patterning in simple spike discharge of Purkinje cells and its relationship to climbing fiber activity. J Neurophysiol 45:933-947. Medline

Eccles JC, Ito M, Szentagothai J (1967) The cerebellum as a neuronal machine. Berlin: Springer.

Gao W, Chen G, Reinert KC, Ebner TJ (2006) Cerebellar cortical molecular layer inhibition is organized in parasagittal zones. J Neurosci 26:83778387. CrossRef Medline

Garwicz M, Andersson G (1992) Spread of synaptic activity along parallel fibres in cat cerebellar anterior lobe. Exp Brain Res 88:615-622. Medline

Gincel D, Regan MR, Jin L, Watkins AM, Bergles DE, Rothstein JD (2007) Analysis of cerebellar Purkinje cells using EAAT4 glutamate transporter promoter reporter in mice generated via bacterial artificial chromosomemediated transgenesis. Exp Neurol 203:205-212. CrossRef Medline

Gundappa-Sulur G, De Schutter E, Bower JM (1999) Ascending granule cell axon: an important component of cerebellar cortical circuitry. J Comp Neurol 408:580-596. CrossRef Medline

Hallem JS, Thompson JH, Gundappa-Sulur G, Hawkes R, Bjaalie JG, Bower JM (1999) Spatial correspondence between tactile projection patterns and the distribution of the antigenic Purkinje cell markers anti-zebrin I and anti-zebrin II in the cerebellar folium crus IIa of the rat. Neuroscience 93:1083-1094. CrossRef Medline

Heck DH, Thach WT, Keating JG (2007) On-beam synchrony in the cerebellum as the mechanism for the timing and coordination of movement. Proc Natl Acad Sci U S A 104:7658-7663. CrossRef Medline

Holtzman T, Rajapaksa T, Mostofi A, Edgley SA (2006) Different responses of rat cerebellar Purkinje cells and Golgi cells evoked by widespread convergent sensory inputs. J Physiol 574:491-507. CrossRef Medline

Huang CM, Wang L, Huang RH (2006) Cerebellar granule cell: ascending axon and parallel fiber. Eur J Neurosci 23:1731-1737. CrossRef Medline

Isope P, Barbour B (2002) Properties of unitary granule cell $\rightarrow$ Purkinje cell synapses in adult rat cerebellar slices. J Neurosci 22:9668-9678. Medline

Isope P, Dieudonne S, Barbour B (2002) Temporal organization of activity in the cerebellar cortex: a manifesto for synchrony. Ann N Y Acad Sci 978:164-174. CrossRef Medline

Jaeger D, Bower JM (1994) Prolonged responses in rat cerebellar Purkinje cells following activation of the granule cell layer: an intracellular in vitro and in vivo investigation. Exp Brain Res 100:200-214. Medline

Ji Z, Hawkes R (1994) Topography of Purkinje cell compartments and mossy fiber terminal fields in lobules II and III of the rat cerebellar cortex: spinocerebellar and cuneocerebellar projections. Neuroscience 61:935954. CrossRef Medline

Kassel J (1980) Superior colliculus projections to tactile areas of rat cerebellar hemispheres. Brain Res 202:291-305. CrossRef Medline

Kassel J, Shambes GM, Welker W (1984) Fractured cutaneous projections 
to the granule cell layer of the posterior cerebellar hemisphere of the domestic cat. J Comp Neurol 225:458-468. CrossRef Medline

Korbo L, Andersen BB, Ladefoged O, Møller A (1993) Total numbers of various cell types in rat cerebellar cortex estimated using an unbiased stereological method. Brain Res 609:262-268. CrossRef Medline

Llinas RR (1982) Radial connectivity in the cerebellar cortex: a novel view regarding the functional organization of the molecular layer. Exp Brain Res 6:189-194. CrossRef

Lonchamp E, Gambino F, Dupont JL, Doussau F, Valera A, Poulain B, Bossu JL (2012) Pre and post synaptic NMDA effects targeting Purkinje cells in the mouse cerebellar cortex. PLoS One 7:e30180. CrossRef Medline

Lu H, Esquivel AV, Bower JM (2009) 3D electron microscopic reconstruction of segments of rat cerebellar Purkinje cell dendrites receiving ascending and parallel fiber granule cell synaptic inputs. J Comp Neurol 514: 583-594. CrossRef Medline

Mathiesen C, Caesar K, Akgören N, Lauritzen M (1998) Modification of activity-dependent increases of cerebral blood flow by excitatory synaptic activity and spikes in rat cerebellar cortex. J Physiol 512:555-566. CrossRef Medline

Nagao S, Kwak S, Kanazawa I (1997) EAAT4, a glutamate transporter with properties of a chloride channel, is predominantly localized in Purkinje cell dendrites and forms parasagittal compartments in rat cerebellum. Neuroscience 78:929-933. CrossRef Medline

Napper RM, Harvey RJ (1988) Number of parallel fiber synapses on an individual Purkinje cell in the cerebellum of the rat. J Comp Neurol 274:168-177. CrossRef Medline

Oz G, Vollmers ML, Nelson CD, Shanley R, Eberly LE, Orr HT, Clark HB (2011) In vivo monitoring of recovery from neurodegeneration in conditional transgenic SCA1 mice. Exp Neurol 232:290-298. CrossRef Medline

Paukert M, Huang YH, Tanaka K, Rothstein JD, Bergles DE (2010) Zones of enhanced glutamate release from climbing fibers in the mammalian cerebellum. J Neurosci 30:7290-7299. CrossRef Medline

Pijpers A, Apps R, Pardoe J, Voogd J, Ruigrok TJ (2006) Precise spatial relationships between mossy fibers and climbing fibers in rat cerebellar cortical zones. J Neurosci 26:12067-12080. CrossRef Medline

Piochon C, Irinopoulou T, Brusciano D, Bailly Y, Mariani J, Levenes C (2007) NMDA receptor contribution to the climbing fiber response in the adult mouse Purkinje cell. J Neurosci 27:10797-10809. CrossRef Medline

Piochon C, Levenes C, Ohtsuki G, Hansel C (2010) Purkinje cell NMDA receptors assume a key role in synaptic gain control in the mature cerebellum. J Neurosci 30:15330-15335. CrossRef Medline

Qiu DL, Knöpfel T (2007) An NMDA receptor/nitric oxide cascade in presynaptic parallel fiber-Purkinje neuron long-term potentiation. J Neurosci 27:3408-3415. CrossRef Medline

Ranck JB Jr (1975) Which elements are excited in electrical stimulation of mammalian central nervous system: a review. Brain Res 98:417-440. CrossRef Medline

Reinert KC, Dunbar RL, Gao W, Chen G, Ebner TJ (2004) Flavoprotein autofluorescence imaging of neuronal activation in the cerebellar cortex in vivo. J Neurophysiol 92:199-211. CrossRef Medline

Reinert KC, Gao W, Chen G, Wang X, Peng YP, Ebner TJ (2011) Cellular and metabolic origins of flavoprotein autofluorescence in the cerebellar cortex in vivo. Cerebellum 10:585-599. CrossRef Medline

Renzi M, Farrant M, Cull-Candy SG (2007) Climbing-fibre activation of NMDA receptors in Purkinje cells of adult mice. J Physiol 585:91-101. CrossRef Medline

Rokni D, Llinas R, Yarom Y (2007) Stars and stripes in the cerebellar cortex: a voltage sensitive dye study. Front Syst Neurosci 1:1. CrossRef Medline

Santamaria F, Bower JM (2005) Background synaptic activity modulates the response of a modeled Purkinje cell to paired afferent input. J Neurophysiol 93:237-250. CrossRef Medline

Santamaria F, Jaeger D, De Schutter E, Bower JM (2002) Modulatory effects of parallel fiber and molecular layer interneuron synaptic activity on Purkinje cell responses to ascending segment input: a modeling study. J Comput Neurosci 13:217-235. CrossRef Medline

Santamaria F, Tripp PG, Bower JM (2007) Feedforward inhibition controls the spread of granule cell-induced Purkinje cell activity in the cerebellar cortex. J Neurophysiol 97:248-263. CrossRef Medline

Sarna JR, Marzban H, Watanabe M, Hawkes R (2006) Complementary stripes of phospholipase Cbeta 3 and Cbeta4 expression by Purkinje cell subsets in the mouse cerebellum. J Comp Neurol 496:303-313. CrossRef Medline

Sasaki K, Bower JM, Llinás R (1989) Multiple Purkinje cell recording in rodent cerebellar cortex. Eur J Neurosci 1:572-586. CrossRef Medline

Serinagaoglu Y, Zhang R, Zhang Y, Zhang L, Hartt G, Young AP, Oberdick J (2007) A promoter element with enhancer properties, and the orphan nuclear receptor RORalpha, are required for Purkinje cell-specific expression of a Gi/o modulator. Mol Cell Neurosci 34:324-342. CrossRef Medline

Shambes GM, Gibson JM, Welker W (1978) Fractured somatotopy in granule cell tactile areas of rat cerebellar hemispheres revealed by micromapping. Brain Behav Evol 15:94-140. CrossRef Medline

Shimamoto K, Lebrun B, Yasuda-Kamatani Y, Sakaitani M, Shigeri Y, Yumoto N, Nakajima T (1998) DL-threo-beta-benzyloxyaspartate, a potent blocker of excitatory amino acid transporters. Mol Pharmacol 53: 195-201. Medline

Shin JH, Linden DJ (2005) An NMDA receptor/nitric oxide cascade is involved in cerebellar LTD but is not localized to the parallel fiber terminal. J Neurophysiol 94:4281-4289. CrossRef Medline

Shin SL, De Schutter E (2006) Dynamic synchronization of Purkinje cell simple spikes. J Neurophysiol 96:3485-3491. CrossRef Medline

Sillitoe RV, Hulliger M, Dyck R, Hawkes R (2003) Antigenic compartmentation of the cat cerebellar cortex. Brain Res 977:1-15. CrossRef Medline

Sims RE, Hartell NA (2005) Differences in transmission properties and susceptibility to long-term depression reveal functional specialization of ascending axon and parallel fiber synapses to Purkinje cells. J Neurosci 25:3246-3257. CrossRef Medline

Stosiek C, Garaschuk O, Holthoff K, Konnerth A (2003) In vivo two-photon calcium imaging of neuronal networks. Proc Natl Acad Sci U S A 100: 7319-7324. CrossRef Medline

Sullivan MR, Nimmerjahn A, Sarkisov DV, Helmchen F, Wang SS (2005) In vivo calcium imaging of circuit activity in cerebellar cortex. J Neurophysiol 94:1636-1644. CrossRef Medline

Tsai MC, Tanaka K, Overstreet-Wadiche L, Wadiche JI (2012) Neuronal glutamate transporters regulate glial excitatory transmission. J Neurosci 32:1528-1535. CrossRef Medline

Valle MS, Eian J, Bosco G, Poppele RE (2008) Cerebellar cortical activity in the cat anterior lobe during hindlimb stepping. Exp Brain Res 187:359372. CrossRef Medline

van Beugen BJ, Gao Z, Boele HJ, Hoebeek F, De Zeeuw CI (2013) Highfrequency burst firing of granule cells ensures transmission at the parallel fiber to Purkinje cell synapse at the cost of temporal coding. Front Neural Circuits 7:1-12. Medline

Voogd J, Pardoe J, Ruigrok TJ, Apps R (2003) The distribution of climbing and mossy fiber collateral branches from the copula pyramidis and the paramedian lobule: congruence of climbing fiber cortical zones and the pattern of zebrin banding within the rat cerebellum. J Neurosci 23:46454656. Medline

Wadiche JI, Jahr CE (2005) Patterned expression of Purkinje cell glutamate transporters controls synaptic plasticity. Nat Neurosci 8:1329-1334. CrossRef Medline

Walter JT, Khodakhah K (2009) The advantages of linear information processing for cerebellar computation. Proc Natl Acad Sci U S A 106 : 4471-4476. CrossRef Medline

Walter JT, Dizon MJ, Khodakhah K (2009) The functional equivalence of ascending and parallel fiber inputs in cerebellar computation. J Neurosci 29:8462-8473. CrossRef Medline

Wang X, Chen G, Gao W, Ebner T (2009) Long-term potentiation of the responses to parallel fiber stimulation in mouse cerebellar cortex in vivo. Neuroscience 162:713-722. CrossRef Medline

Wang X, Chen G, Gao W, Ebner TJ (2011) Parasagittally aligned, mGluR1dependent patches are evoked at long latencies by parallel fiber stimulation in the mouse cerebellar cortex in vivo. J Neurophysiol 105:17321746. CrossRef Medline

Wise AK, Cerminara NL, Marple-Horvat DE, Apps R (2010) Mechanisms of synchronous activity in cerebellar Purkinje cells. J Physiol 588:23732390. CrossRef Medline

Wu HS, Sugihara I, Shinoda Y (1999) Projection patterns of single mossy fibers originating from the lateral reticular nucleus in the rat cerebellar cortex and nuclei. J Comp Neurol 411:97-118. CrossRef Medline

Yang G, Chen G, Ebner TJ, Iadecola C (1999) Nitric oxide is the predomi- 
nant mediator of cerebellar hyperemia during somatosensory activation in rats. Am J Physiol 277:R1760-R1770. Medline

Yu QX, Ebner TJ, Bloedel JR (1985) Electrophysiological study of the corti- conuclear projection in the cat cerebellum. Brain Res 327:121-134. CrossRef Medline 